\title{
Unraveling Complexity in the Solid Form Screening of a Pharmaceutical Salt: Why so Many Forms? Why so Few?
}

Published as part of a Crystal Growth and Design virtual special issue Honoring Prof. William Jones and His Contributions to Organic Solid-State Chemistry

Doris E. Braun, ${ }^{\| \odot ~ S r e e n i v a s ~ R . ~ L i n g i r e d d y, ~}{ }^{\dagger}$ Mark D. Beidelschies, ${ }^{\ddagger}$ Rui Guo, ${ }^{\S}$ Peter Müller, Sarah L. Price, ${ }^{\$}(0)$ and Susan M. Reutzel-Edens ${ }^{*} \dagger+0$

"Institute of Pharmacy, University of Innsbruck, Innrain 52c, 6020 Innsbruck, Austria

${ }^{\dagger}$ Eli Lilly and Company, Indianapolis, Indiana 46285, United States

${ }^{\ddagger}$ Eurofins Lancaster Laboratories, PSS, Indianapolis, Indiana 46285, United States

${ }^{\S}$ Department of Chemistry, University College London, 20 Gordon Street, London WC1H 0AJ, U.K.

${ }^{\#}$ X-Ray Diffraction Facility, MIT Department of Chemistry, 77 Massachusetts Avenue, Cambridge, Massachusetts 02139, United States

Supporting Information

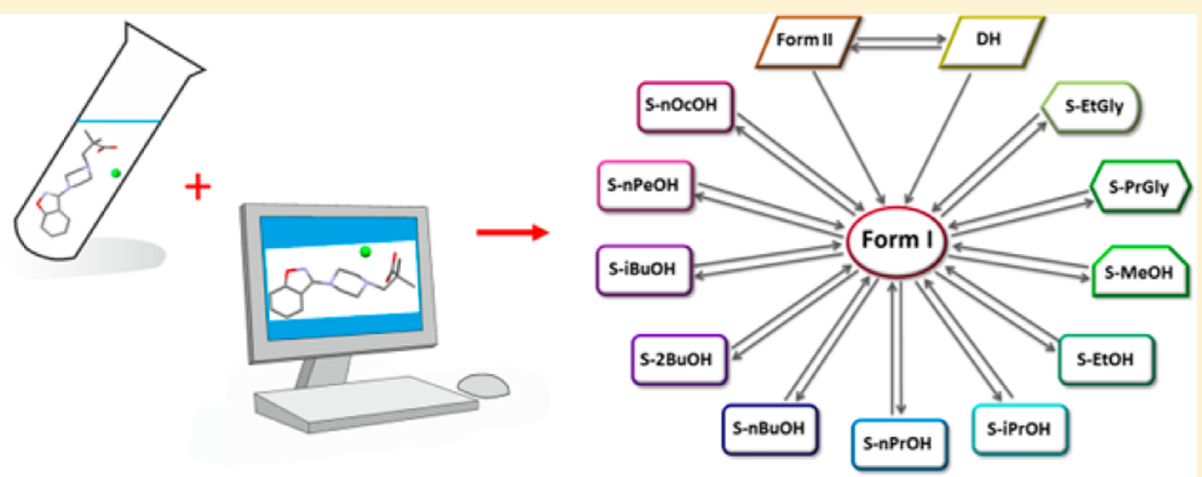

ABSTRACT: The solid form landscape of 5-HT2a antagonist 3-(4-(benzo[d]isoxazole-3-yl)piperazin-1-yl)-2,2-dimethylpropanoic acid hydrochloride $(\mathrm{B} 5 \mathrm{HCl})$ proved difficult to establish. Many crystalline materials were produced by solid form screening, but few forms readily grew high quality crystals to afford a clear picture or understanding of the solid form landscape. Careful control of crystallization conditions, a range of experimental methods, computational modeling of solvate structures, and crystal structure prediction were required to see potential arrangements of the salt in its crystal forms. Structural diversity in the solid form landscape of $\mathrm{B} 5 \mathrm{HCl}$ was apparent in the layer structures for the anhydrate polymorphs (Forms I and II), dihydrate and a family of solvates with alcohols. The alcohol solvates, which provided a distinct packing from the neat forms and the dihydrate, form layers with conserved hydrogen bonding between $\mathrm{B} 5 \mathrm{HCl}$ and the solvent, as well as stacking of the aromatic rings. The ability of the alcohol hydrocarbon moieties to efficiently pack between the layers accounted for the difficulty in growing some solvate crystals and the inability of other solvates to crystallize altogether. Through a combination of experiment and computation, the crystallization problems, form stability, and desolvation pathways of $\mathrm{B} 5 \mathrm{HCl}$ have been rationalized at a molecular level.

\section{INTRODUCTION}

The oral delivery of a drug from a solid dosage form depends on the properties of its solid state. As crystallinity usually confers upon the drug substance advantages, such as impurity rejection, improved handling characteristics, and generally greater physical and chemical stability, the selection of a crystalline form is one of the first steps taken in drug development to transform a molecule to a safe and efficacious medicine. The pharmaceutical industry must have a thorough knowledge of the solid-state forms of the drug substance and their properties in order to identify one that is developable, and potentially commercializable, for a drug product. ${ }^{1}$ Both the form of interest, usually that which has the lowest free energy (i.e., is thermodynamically stable), and other competitive forms (those to avoid) are necessary inputs to designing downstream crystallization and formulation processes. This information,

Received: June 16, 2017

Revised: July 28, 2017

Published: September 7, 2017 


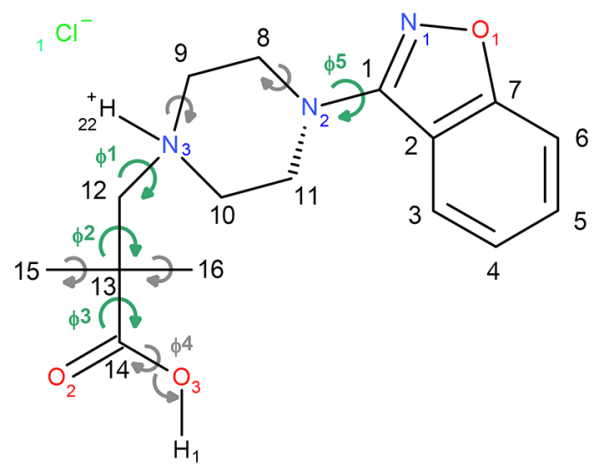

(a)
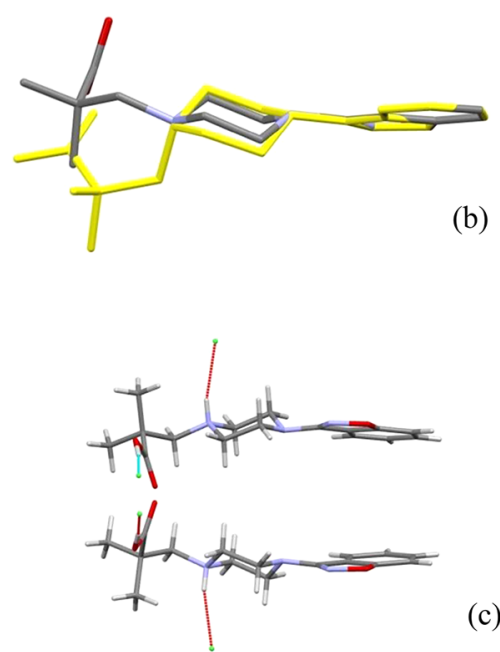

Figure 1. (a) The molecular structure and conformational flexibility of $\mathrm{B} \mathrm{H}^{+} \mathrm{Cl}^{-}$. The green arrows denote the torsion angles that can change substantially and so were explicitly varied in the CrystalPredictor search and the gray arrows those that were also allowed to vary in the CrystalOptimizer refinement; (b) overlay of two representative conformational regions: ee (colored by element) from anhydrous Form I/solvates and $e a$ (in yellow) seen in Form II/dihydrate; (c) the two chiral ee conformations of the $\mathrm{BSH}^{+}$cation.

which is also essential for setting drug substance and drug product control strategies, is frequently compiled from solid form screening output in the form of a solid form landscape, a map of the observed forms highlighting their structural relationships, crystallization conditions, and interconversion pathways.

Solid form screens are designed to induce crystallization under a variety of conditions. Because it is not yet possible to predict if a molecule will crystallize, let alone in what forms, the crystallization screening exercise will generally continue until a judgment is made that sufficient crystallization "space" has been explored in the search for thermodynamically competitive forms. For molecules that crystallize with ease in but a few forms (polymorphs, hydrates), constructing a solid form landscape can be a straightforward task. Quite often, however, compounds exhibit extreme solubility properties, crystallize too slowly (or rapidly), or are chemically unstable, making it difficult to meaningfully survey diverse crystallization conditions. Accounting for the unpredictable effects of impurities ${ }^{2,3}$ on crystallization outcomes only exacerbates the problem. For some compounds, the materials generated at small scale and under suboptimal conditions typical of a polymorph screen may be poorly crystalline or disordered. They may be solid solutions or nonstoichiometric solvates of varying composition or phase mixtures, all of which complicate form identification by higher throughput powder X-ray diffraction (PXRD) or Raman methods. Scale-up of the form hits to even milligram scale is often not trivial, particularly for impurity phases lacking a "recipe" from the screen or unstable forms that disappear ${ }^{4}$ once a more stable form nucleates. All of these factors may confound the generation of a reliable solid form landscape on the time scales of commercial solid form selection, especially when material is in limited supply.

Elucidating the sometimes complex solid form landscapes of modern pharmaceuticals can place a significant burden on the increasingly limited resources dedicated to solid form screening in industry, a challenge that can only be met by thoughtful application of a range of experimental, and more recently, computational tools. Herein we show how a combination of well-designed experiments and computational chemistry was used to overcome many hurdles in constructing the solid form landscape of 3-(4-(benzo[d]isoxazole-3-yl)piperazin-1-yl)-2,2dimethylpropanoic acid hydrochloride ( $\mathrm{B} 5 \mathrm{HCl}$, Figure 1a). As an amphoteric molecule capable of forming acid and base salts, this 5-HT2a antagonist was initially developed for the oral treatment of depression and sleep disorders as the $\mathrm{HCl}$ salt. Comprehensive solid form screening revealed that the $\mathrm{B} 5 \mathrm{HCl}$ salt forms two nonsolvated polymorphs (Forms I and II), a dihydrate and several alcohol solvates, some of which were difficult to grow into single crystals suitable for study by X-ray diffraction. In the presence of water, $\mathrm{B} 5 \mathrm{HCl}$ showed a strong tendency to disproportionate, highlighting a potentially significant risk to control of the solid-state form in the drug product. The parent compound (B5), in contrast to $\mathrm{B} 5 \mathrm{HCl}$, is monomorphic, showing a particularly simple crystallization behavior, and was ultimately chosen for the development of a commercial product. We previously used B5 as a model compound ${ }^{5}$ to test the value of combining computational crystal structure prediction (CSP) methods with experimental solid form screening. ${ }^{6}$ This rationalized there being only one crystalline form of neutral B5, whereas a closely related molecule from the same drug discovery program had multiple forms, including solvates. ${ }^{5}$

Owing to the generally poor solubility of $\mathrm{B} 5 \mathrm{HCl}$ in most organic solvents, the comprehensive solid form screen of $\mathrm{B} 5 \mathrm{HCl}$ that used neat Form I as the starting material yielded mostly Form I. Attempts to render $\mathrm{B} 5 \mathrm{HCl}$ amorphous in order to increase the solubility and rid the starting material of Form I failed, with lyophilization instead yielding poorly crystalline Form I and heating triggering loss of $\mathrm{HCl}(\mathrm{g})$ and chemical decomposition. As a result, water or supersolvents (e.g., dimethyl sulfoxide) were often introduced to ensure that Form I was fully dissolved prior to recrystallization. The presence of water in the crystallization medium was found to be problematic, however, as $\mathrm{B} 5 \mathrm{HCl}$ tended to disproportionate in mostly aqueous solutions yielding B5 Form I.

Successful solid form screening of $\mathrm{B} 5 \mathrm{HCl}$ required overcoming the challenges presented by the poor solubility properties of the Form I starting material, the susceptibility of the $\mathrm{HCl}$ salt to disproportionate in water, the chemical 
instability of B5 at higher temperatures, and the relative ease with which $\mathrm{B} 5 \mathrm{HCl}$ Form I seemed to crystallize. The difficulties did not end with the customized experimental solid form screen producing the first PXRD evidence of a range of crystal forms, however; the newly discovered forms, most of which were suspected to be solvates, proved especially difficult to identify as crystallized from the "unoptimized" experiments that solid form screens generally rely upon to promote different nucleation pathways. Crystals of the $\mathrm{B} 5 \mathrm{HCl}$ solvates were frequently elongated and very thin, producing powder patterns characterized in most cases by a single family of diffraction peaks. The low angle reflections produced by layer stackings were reasonably diagnostic of solvate formation. Still, identifying specific solvate phases (when more than one solvent was used to crystallize $\mathrm{B} 5 \mathrm{HCl}$ ) and the structural relationships between them was nearly impossible for crystalline products generated from the solid form screen and characterized by a relatively quick reflection PXRD method.

This paper seeks to establish the range of crystalline forms produced during the solid form screening of $\mathrm{B} 5 \mathrm{HCl}$, using computation to help suggest the solvate structures and principles behind the solvate formation of this salt. The structures and stability relationships between $\mathrm{B} 5 \mathrm{HCl}$ Forms I and II, dihydrate, nine 1:1 alcohol solvates $(\mathrm{MeOH}, \mathrm{EtOH}$, $\mathrm{nPrOH}, \mathrm{iPrOH}, \mathrm{nBuOH}, \mathrm{iBuOH}, 2 \mathrm{BuOH}, \mathrm{nPeOH}, \mathrm{nOcOH})$ and two 2:1 dialcohol solvates (ethylene and propylene glycol) are reported. We use crystal structure prediction (CSP) methods to investigate the crystal packings of $\mathrm{B} 5 \mathrm{HCl}$ that are thermodynamically competitive with the observed structures, provide insight into the solid form screen for polymorphs of $\mathrm{B} 5 \mathrm{HCl}$, and determine how the possible packing modes of $\mathrm{B} 5 \mathrm{HCl}$ influence the structures of the solvated forms. This extends work on relating the crystal energy landscape of the neat compound to the tendency to form solvates. ${ }^{5,7}$

\section{MATERIALS AND METHODS}

2.1. Materials. $\mathrm{B} 5 \mathrm{HCl}$ Form I (purity > 99\%) was obtained from Lilly Research Laboratories. All solvents, purchased from different suppliers and used for crystallization screening, were reagent grade (>99\% purity).

2.2. Solid Form Screening/Scale-Up. Solid form screening experiments were performed using crystalline Form I as the starting material and encompassed a range of industry-standard techniques, including solvent evaporation, cooling crystallization, standard and reverse antisolvent addition, vapor diffusion, slurry equilibration, $\mathrm{pH}$ swing, and cross seeding. The solvent-based screening experiments from over 35 solvents and mixtures thereof were tailored to the solubility properties of $\mathrm{B} 5 \mathrm{HCl}$ and covered a range of temperatures. Nonsolvent methods, including thermal desolvation and thermal cycling, were also explored. Details of the crystallization conditions surveyed in the solid form screen, along with the scale-up of the newly discovered crystal forms of $\mathrm{B} 5 \mathrm{HCl}$, are reported in the Supporting Information.

2.3. Single Crystal X-ray Diffraction. Three-dimensional X-ray diffraction data ( $\varphi$-and $\omega$-scans) were collected on either a Bruker three-circle diffractometer coupled to a Bruker SMART-6000 CCD detector using Mo $\mathrm{K} \alpha$ radiation $(\lambda=0.71073 \AA)$ or $\mathrm{Cu} \mathrm{K} \alpha$ radiation $(\lambda=1.54178 \AA)$ from a microfocus sealed tube equipped with a graphite monochromator or on a Bruker three-circle diffractometer coupled to a Bruker Photon-1000 CMOS detector using $\mathrm{Cu} \mathrm{K} \alpha$ radiation $(\lambda=1.54178 \AA)$ from an $\mathrm{I} \mu \mathrm{S}$ microsource. Details of the structure refinement are provided in section 1 of the Supporting Information.

2.4. Powder X-ray Diffraction. PXRD patterns were measured at room temperature in reflection mode using a Bruker D8 Advance Xray powder diffractometer and in transmission mode for lightly ground samples loaded into $0.7 / 1 \mathrm{~mm}$ borosilicate capillaries using a PANalytical Empyrean diffractometer. The diffraction patterns recorded in transmission were indexed ${ }^{8}$ with DICVOL04, and the space group was determined based on a statistical assessment of systematic absences. ${ }^{9,10}$ Pawley fits ${ }^{11}$ and Rietveld ${ }^{12}$ refinement were performed with Topas Academic V5. ${ }^{13}$ For more details see section 2 of the Supporting Information.

2.5. Solid-State NMR Spectroscopy. ${ }^{13} \mathrm{C}$ cross-polarization/ magic angle spinning NMR (ssNMR) spectra were obtained for polycrystalline samples packed in $4 \mathrm{~mm}$ zirconia rotors using a Bruker Avance III 400 wide-bore NMR spectrometer operating at ${ }^{1} \mathrm{H}$ and ${ }^{13} \mathrm{C}$ frequencies of 400.131 and $100.623 \mathrm{MHz}$, respectively. The sample spinning speed was set to $10 \mathrm{kHz}$ and controlled to within $\pm 2 \mathrm{~Hz}$ using a Bruker MAS-II controller. A Bruker $4 \mathrm{~mm}$ double resonance probe was tuned to ${ }^{1} \mathrm{H}$ and ${ }^{13} \mathrm{C}$ frequencies and a $4.0 \mathrm{~ms}$ linear $\mathrm{RF}$ power ramp applied on the ${ }^{1} \mathrm{H}$ channel was used for crosspolarization. ${ }^{14}{ }^{1} \mathrm{H}$ decoupling at an RF power corresponding to 100 $\mathrm{kHz}$ was achieved using the SPINAL64 pulse sequence. ${ }^{15}$ Spinning sidebands were eliminated by a five-pulse total sideband suppression (TOSS) sequence. ${ }^{16}$ The acquisition time was set to $34 \mathrm{~ms}$, and spectra were acquired over a spectral width of $30 \mathrm{kHz}$ with a recycle delay of $5 \mathrm{~s}$. Unless specified otherwise, the sample temperature was regulated to $24{ }^{\circ} \mathrm{C}$ in order to minimize frictional heating caused by sample spinning. ssNMR spectra of the labile monoalcohol solvates were collected at $0{ }^{\circ} \mathrm{C}$ when needed to minimize conversion to Form I during the data acquisition. The ${ }^{13} \mathrm{C}$ chemical shifts were externally referenced $( \pm 0.05 \mathrm{ppm})$ to the proton-decoupled ${ }^{13} \mathrm{C}$ peak of neat (liquid) tetramethylsilane via the high-field resonance of adamantane $(\delta=29.5 \mathrm{ppm})$.

2.6. Thermal Analysis. Differential thermal/thermogravimetric analyses were carried out on a TA Instruments simultaneous differential scanning calorimetry-thermogravimetric analysis (DSCTGA) model Q600 SDT. Samples were heated in open aluminum pans from ambient temperature to $225-300{ }^{\circ} \mathrm{C}$ at $10{ }^{\circ} \mathrm{C} \mathrm{min}{ }^{-1}$ with a nitrogen $\left(\mathrm{N}_{2}\right)$ purge of $100 \mathrm{~mL} \mathrm{~min}{ }^{-1}$. The temperature was calibrated with indium. Weight calibration was performed with manufacturersupplied standards and verified against sodium tartrate dihydrate desolvation. Temperature difference and weight loss plots were generated using TA Instruments Universal Analysis 2000 software, Version 4.4A. DSC was conducted using a TA Instruments Q1000 DSC. Samples were equilibrated at $25{ }^{\circ} \mathrm{C}$ in hermetically sealed aluminum pans and then heated to $300{ }^{\circ} \mathrm{C}$ at $10{ }^{\circ} \mathrm{C} \mathrm{min}{ }^{-1}$ with a 50 $\mathrm{mL} \min ^{-1} \mathrm{~N}_{2}$ purge. The temperature and heat flow were calibrated against indium melting. Variable heating rate DSC studies were conducted as follows: Samples encapsulated in hermetically sealed aluminum pans were equilibrated at $25{ }^{\circ} \mathrm{C}$, heated to $300{ }^{\circ} \mathrm{C}$ at 5,10 , 20, and $50{ }^{\circ} \mathrm{C} \mathrm{min}{ }^{-1}$, all under a $50 \mathrm{~mL} \mathrm{~min}{ }^{-1} \mathrm{~N}_{2}$ purge.

Variable heating rate DSC experiments were also performed with a Diamond DSC (PerkinElmer Norwalk, Ct., USA), controlled by Pyris 7.0 software. Using a UM3 ultramicrobalance (Mettler, Greifensee, $\mathrm{CH}$ ), samples of approximately $1 \mathrm{mg}$ were weighed into closed Tzero capsules. The samples were heated using rates ranging from 10 to 300 ${ }^{\circ} \mathrm{C} \mathrm{min}^{-1}$, with dry $\mathrm{N}_{2}$ as the purge gas (purge: $20 \mathrm{~mL} \mathrm{~min}^{-1}$ ). The instrument was calibrated for temperature with pure benzophenone $\left(\mathrm{mp} 48.0^{\circ} \mathrm{C}\right.$ ) and caffeine $\left(236.2^{\circ} \mathrm{C}\right)$, and the energy calibration was performed with indium $\left(\mathrm{mp} 156.6^{\circ} \mathrm{C}\right.$, heat of fusion $\left.28.45 \mathrm{~J} \mathrm{~g}^{-1}\right)$. The errors in the stated onset temperature and enthalpy values were calculated at $95 \%$ confidence intervals $(\mathrm{CI})$ and are based on at least three measurements.

2.7. Calculation and Analysis of the Crystal Energy Landscape. The conformational analysis (Supporting Information, section 3.1) showed that there was a large region of conformational space of the isolated cation, divided into four regions according to whether the substituents of the two piperazine ring nitrogens were axial $(a)$ or equatorial $(e)$, that was sufficiently low in energy to plausibly occur in crystal structures. ${ }^{17}$ The benzisoxazole and piperazine rings are nearly coplanar, being equatorial at $\mathrm{N} 2$ in all observed neutral and salt structures of B5, in line with the general preference of extended flat conformations in crystal packing. ${ }^{9}$ The search only considered the two conformational regions corresponding 
(a)

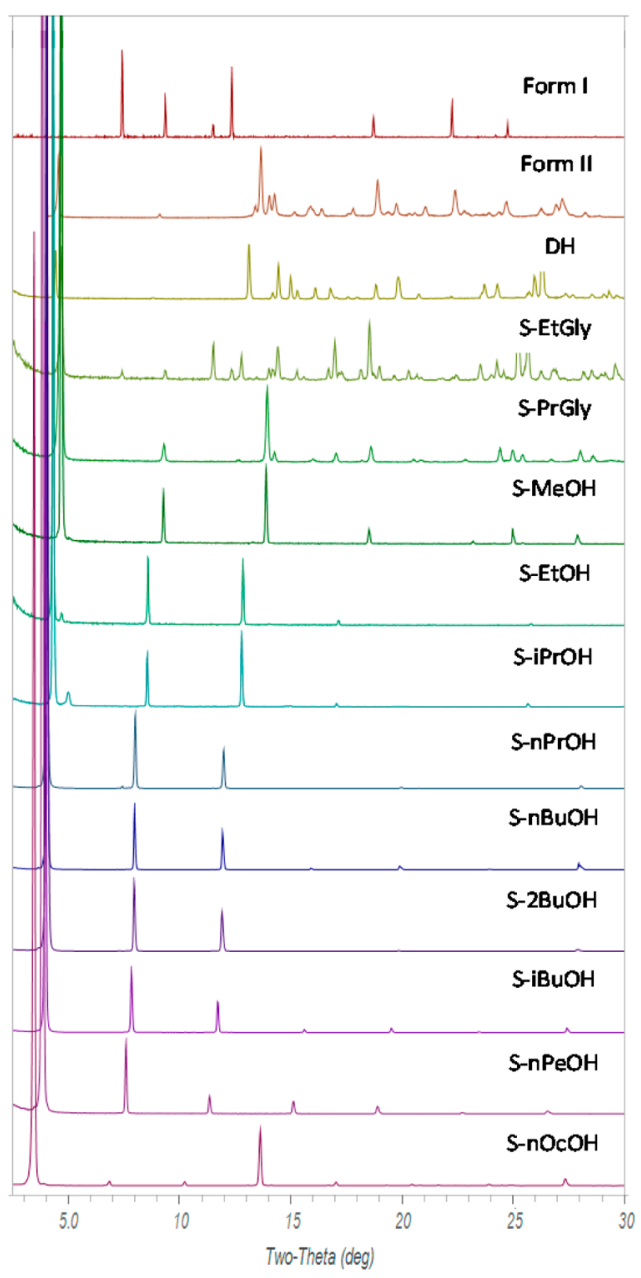

(b)

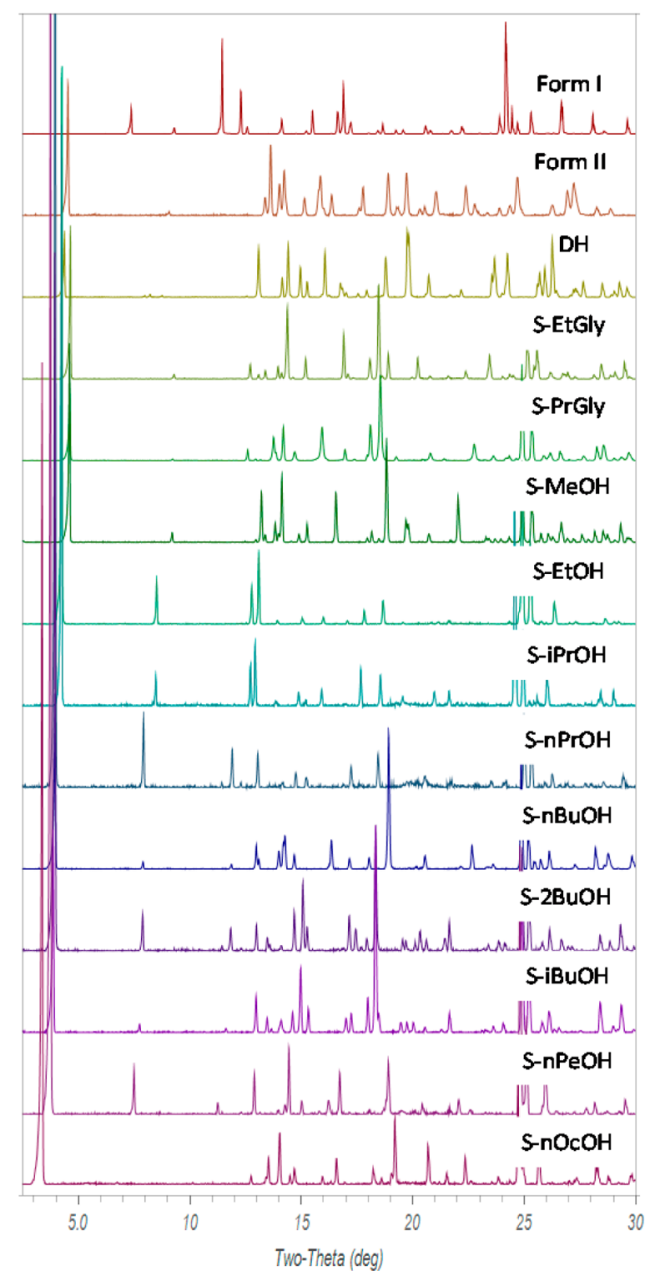

Figure 2. Powder diffractograms of $\mathrm{B} 5 \mathrm{HCl}$ crystal forms measured (a) by a quick reflection method (flat plate) during the solid form screen and (b) by an optimized capillary (transmission) method following form scale-up.

to the observed structures, i.e., with N2 equatorial and N3 either axial or equatorial (ee and $e a$ respectively). The search was performed using CrystalPredictor $\mathrm{v} 1.6^{19}$ covering the 59 most common space groups with $Z^{\prime}=1$. The structures were further refined using CrystalOptimizer v2.2 $2^{20}$ using a distributed multipole representation of the charge density $^{21}$ within DMACRYS. ${ }^{22}$ The conformational energies and atomic charges or distributed multipoles used were calculated at the PBE0/6-31G $(\mathrm{d}, \mathrm{p})$ level, and all other intermolecular forces were modeled in an atom-atom exp-6 form using the FIT potential. ${ }^{22}$ Full details are in the Supporting Information, which also includes an analysis of the effects of varying the potential model to use the Williams exp-6 potential parameters ${ }^{23}$ with recently developed $\mathrm{Cl}^{-}$ parameters $^{24}$ and performing the molecular ab initio calculations within a polarizable continuum ${ }^{25}$ to partially mimic the effect of polarization within the crystal lattice.

The same distributed multipole intermolecular potential method was used to model the solvates which were characterized by single crystal diffraction, and also in computational desolvation calculations. Possible solvent packings in the disordered solvates were proposed starting with the experimental solvate structures, adding/removing $-\mathrm{CH}_{3}$ groups to/from the solvent molecules (see Supporting Information, section 5). These structures were optimized with periodic density functional calculations $\left(\mathrm{CASTEP}^{26}\right)$. The Perdew-BurkeErnzerhof (PBE) generalized gradient approximation (GGA) exchange-correlation density functional ${ }^{27}$ and ultrasoft pseudopotentials, ${ }^{28}$ with the addition of either the Tkatchenko and Scheffler (TS $)^{29}$ or Grimme (D2) ${ }^{30}$ semiempirical dispersion correction, were applied. NMR shielding calculations were performed on PBE-TS optimized structural models using the CASTEP NMR code and on the fly pseudopotentials. ${ }^{31}$ The CASTEP computed shielding constants, $\sigma_{\text {calo }}$ were converted to chemical shifts, $\delta_{\text {calo }}$ according to $\delta_{\text {calc }}=\sigma_{\text {ref }}-\sigma_{\text {calc }}$ using a reference value, $\sigma_{\text {ref, }}$ taken from the zero intercepts of the fits of the calculated shielding versus experimental chemical shift plot $\left(\sigma_{\text {CASTEP }}=-x \cdot \delta_{\exp }+\sigma_{\text {ref }}\right)$. Full details are in the Supporting Information (section C).

The hydrogen bonding motifs and packing similarities between the $\mathrm{B} 5 / \mathrm{B} 5 \mathrm{HCl}$ crystal structures were analyzed using Mercury $^{32}$ and XPac. $^{33}$

\section{RESULTS}

3.1. Experimental Solid Form Landscape. The solid form screen of $\mathrm{B} 5 \mathrm{HCl}$ comprised more than 450 experiments (detailed in Supporting Information, section 11), most of which were solution-based recrystallizations designed around the overall poor solubility of the $\mathrm{HCl}$ salt. Attempts to render $\mathrm{B} 5 \mathrm{HCl}$ amorphous to overcome the solubility limitations yielded Form I instead, albeit in poorly crystalline form. Given the low solubility of $\mathrm{B} 5 \mathrm{HCl}$ in most solvents and the strong tendency of Form I to crystallize, automated platforms to rapidly survey crystallization conditions using preprogrammed routines were abandoned early on in favor of manual methods, where measures could be taken to ensure that the Form I starting material was completely dissolved prior to recrystallization from each solution. Still, Form I was identified by flat-plate 
(reflection) PXRD analysis as the predominant form in the isolated solid products, having been obtained from virtually every solvent depending on the conditions.

$\mathrm{B} 5 \mathrm{HCl}$ dihydrate was discovered during the solubility and stability profiling of Form I in water. Solution-mediated conversion of Form I to the more stable dihydrate was only possible in aqueous suspensions maintained at low $\mathrm{pH}$. Above the $\mathrm{pH}_{\max }(\mathrm{pH} \approx 1.8$, Figure S56), the $\mathrm{HCl}$ salt disproportionated causing the parent compound (B5) to rapidly crystallize in its only known form, B5 Form I. Despite its greater thermodynamic stability in water at low $\mathrm{pH}$ (Table S25), the dihydrate was surprisingly elusive, having only on rare occasions crystallized from aqueous-organic solutions and usually concomitantly with other forms during the solid form screen.

Recrystallization of $\mathrm{B} 5 \mathrm{HCl}$ from alcohols typically yielded extremely thin platy crystals (Supporting Information), which were clearly neither Form I nor the dihydrate, but almost impossible to identify by flat plate PXRD. Shown in Figure 2a are representative powder patterns generated during the solid form screen, where at most a few sharp, evenly spaced peaks were observed for materials crystallized from monoalcohols. While similar in habit and seemingly related by diffraction, the platy crystals were not identical, with the few diffraction peaks shifting to progressively lower angles (larger $d$-spacings) as the size of the alcohol increased. Unfortunately, gentle grinding of these materials to minimize the effects of preferred orientation did little to improve their PXRD patterns; the crystals were seemingly too thin.

The platy crystals were suspected to be alcohol solvates of $\mathrm{B} 5 \mathrm{HCl}$ based not only on the variation in PXRD peak positions, but also TGA data showing significant low temperature weight losses for these materials on heating (Figure S57) and their conversion to Form I on standing in the solid state. Solvate formation was subsequently confirmed for wet cake samples of these forms reproduced from the screening recipes at larger scale by the appearance of solvent peaks in the ${ }^{13} \mathrm{C}$ CP/MAS NMR spectra, Figure 3. While ssNMR spectroscopy is not normally required to identify forms coming out of solid form screens, this technique, in being sensitive to short-range order, was indispensable for fingerprinting the solid-state forms of $\mathrm{B} 5 \mathrm{HCl}$ given how poorly diffracting the solvates were as initially crystallized.

The signature low angle PXRD reflections observed for the alcohol solvates, along with their remarkably similar ssNMR spectra (except for the solvent peaks), provided seemingly clear evidence of the structural relationships across the homologous series. However, the stoichiometry of the solvates was not immediately obvious from the typically mixed phases coming out of the solid form screen. Moreover, identifying the specific solvate phases crystallized from alcohol mixtures, let alone their structural relationships to the other $\mathrm{B} 5 \mathrm{HCl}$ crystal forms, was nearly impossible short of solving their crystal structures. Therefore, a concerted effort was made to grow larger (thicker) single crystals suitable for structure determination. With careful manipulation of the crystallization conditions to solubilize $\mathrm{B} 5 \mathrm{HCl}$, minimizing the water present in the medium, single crystals were grown for most of the alcohol solvates (Supporting Information) of sufficient size and quality for structure solution to at least be attempted (Section 3.2). Extended capillary PXRD analysis was performed for suspensions of the freshly crystallized and gently ground solvates, yielding high quality powder patterns (Figure $2 \mathrm{~b}$ ) to

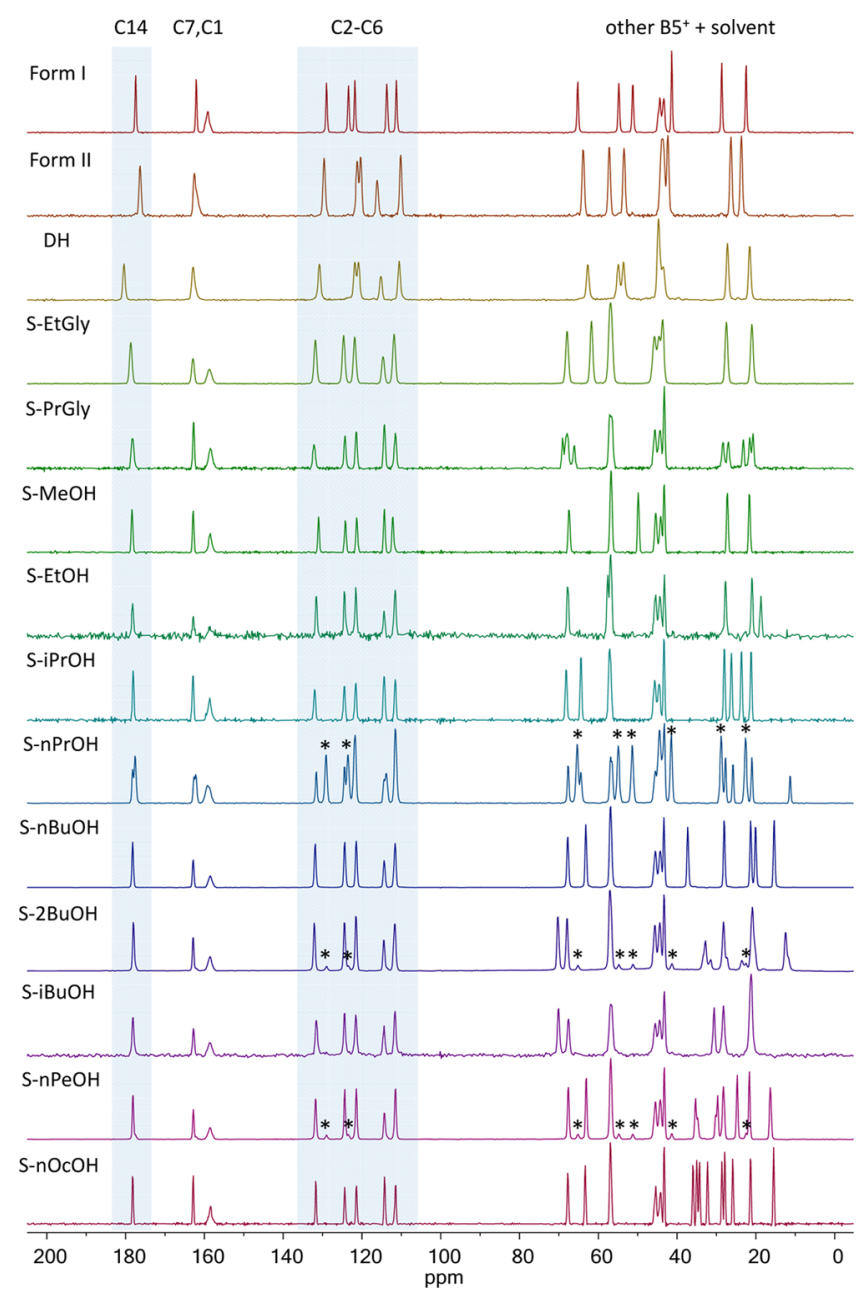

Figure 3. ${ }^{13} \mathrm{C} \mathrm{CP} / \mathrm{MAS}$ NMR spectra of $\mathrm{B} 5 \mathrm{HCl}$ crystal forms. Highlighted are the $\mathrm{C} 2-\mathrm{C} 6$ and $\mathrm{C} 14$ peaks from the $\mathrm{B}^{2} \mathrm{H}^{+}$ benzisoxazole and carboxylic acid carbons, respectively. ssNMR spectra were collected, when needed, at $0{ }^{\circ} \mathrm{C}$ to minimize conversion of the alcohol solvates to Form I (*) during data acquisition.

unequivocally differentiate all of the $\mathrm{B} 5 \mathrm{HCl}$ forms that would comprise the solid form landscape. Once harvested from the crystallizing solutions, these materials were also rapidly characterized by TGA-Fourier transform infrared spectroscopy (FTIR) and/or solution ${ }^{1} \mathrm{H}$ NMR spectroscopy to confirm the solvate stoichiometry. $\mathrm{B} 5 \mathrm{HCl}$ was shown to reliably form 1:1 solvates with monoalcohols and 2:1 solvates with dialcohols.

Having established an apparently strong tendency of $\mathrm{B} 5 \mathrm{HCl}$ to form alcohol solvates, the "optimized" crystallization procedure was used with other larger alcohols, including $t$ butanol, isopentyl alcohol, cyclohexanol, and $n$-heptanol, as well as nonalcohols (acetone, methyl ethyl ketone, acetonitrile, $n$ butyl acetate). The first series of experiments was intended to establish the range of alcohols capable of forming solvates, while the second tested the selectivity of $\mathrm{B} 5 \mathrm{HCl}$ for forming solvates with alcohols. Although there was some evidence for solvate formation with isopentyl alcohol and cyclohexanol (Table S24), B5HCl failed to form a solvate with $t$-butanol, $n$ heptanol, or any of the nonalcohols. Attempts to promote crystal growth by introducing seeds of S-MeOH or S-iPrOH to supersaturated higher alcohol solutions yielded Form I in all cases, except cyclohexanol, where a solvate was identified by PXRD (Table S26). Isostructural seeding experiments were 
also performed following the observation of a unique crystal packing of S-MeOH relative to the other monoalcohol solvates. $\mathrm{B} 5 \mathrm{HCl}$ could not be induced to crystallize in essentially the S$\mathrm{MeOH}$ structure from higher monoalcohols or in the higher alcohol solvate packing from methanol (Table S26). The alternate packing motifs did, however, appear by single crystal $\mathrm{X}$-ray diffraction to be disorder components in some of the solvate crystal structures (Section 3.2).

To complement the solvent-based screening methods, desolvation (or dehydration) and solvent exchange were explored. The dihydrate was dried under a variety of conditions, many of which produced $\mathrm{B} 5 \mathrm{HCl}$ Form I. However, dehydration at room temperature below $4 \%$ relative humidity $(\mathrm{RH})$ afforded a new, nonsolvated polymorph, Form II (Figure S60b). Form II was found to be very unstable, immediately reforming the dihydrate at $\mathrm{RH}$ values of $\sim 8 \%$ and above. If held below $8 \%$ $\mathrm{RH}$, a slower transformation of Form II to Form I was observed. Desolvation of the alcohol solvates at temperatures ranging from above RT to $75{ }^{\circ} \mathrm{C}$ in all cases yielded Form I (Table S27). Most of the alcohol solvates were sufficiently labile that conversion to Form I also occurred on standing at RT, although based on gravimetric vapor sorption analysis, this process appears to be accelerated at moderate to high $\mathrm{RH}$ (Figure S59). For solvates, such as $\mathrm{S}-\mathrm{iPrOH}$ and $\mathrm{S}-\mathrm{nPeOH}$, there was some evidence of water exchange (up to 20\%) into the solvate crystal prior to conversion to Form I.

The comprehensive experimental screen of $\mathrm{B} 5 \mathrm{HCl}$ revealed a solid form landscape of at least 14 forms: neat Forms I and II, a dihydrate, 9 alcohol monosolvates (1:1) from methanol, ethanol, isopropanol, $n$-propanol, $n$-butanol, 2-butanol, $i$ butanol, $n$-pentanol, and $n$-octanol, and 2 hemisolvates (2:1) from ethylene glycol and propylene glycol, Figure 4. $\mathrm{B} 5 \mathrm{HCl}$

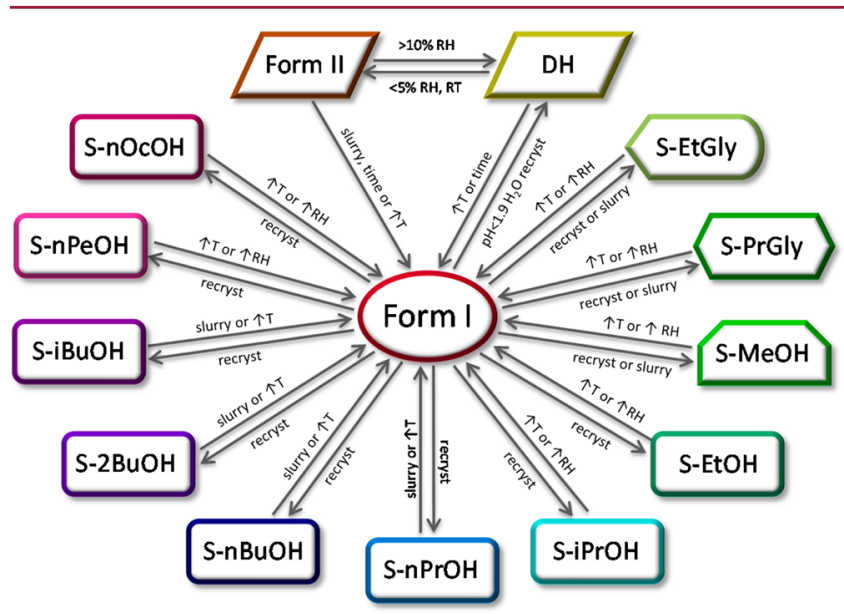

Figure 4. Experimental solid form landscape of $\mathrm{B} 5 \mathrm{HCl}$, summarizing the forms discovered by solid form screening and showing routes to their production, interconversion pathways and packing relationships (the same box shape implies a similar crystal structure). Putative isopentyl alcohol and cyclohexanol solvates are not shown.

may very well form other alcohol solvates, with evidence for solvate formation seen with isopentyl alcohol and cyclohexanol. Given the difficulty in crystallizing and preserving the solvates, the likelihood of having missed one that is stable was considered low. Thus, with Form I so readily crystallizing under diverse conditions and all known solvates readily desolvating to this neat crystal form, alcohol solvate formation was not further explored as a means to pharmaceutically relevant polymorphs of $\mathrm{B} 5 \mathrm{HCl}$.

3.2. Crystal Structure Analysis of $\mathrm{B} 5 \mathrm{HCl}$ Form I, Form II, Dihydrate and Solvates. The crystal packing of $\mathrm{B} 5 \mathrm{HCl}$ in Form I, Form II, the dihydrate, most of the monoalcohol solvates, and both dialcohol solvates is contrasted in Figure 5. B5 is protonated in each structure, with the acidic protons of $\mathrm{B} \mathrm{H}^{+}$residing on the carboxylic acid and the most basic nitrogen, N3, in accord with the experimentally determined $\mathrm{p} K_{\mathrm{a}}$ values. The internal piperazine ring in $\mathrm{BSH}^{+}$adopts a chair conformation in all structures with the substituents on the piperazine ring nitrogens, $\mathrm{N} 2$ and $\mathrm{N} 3$, occupying equatorial positions (denoted $e e$ ) in both Form I and the alcohol solvates and the N3 substituent being axial (conformational region ea) in Form II and the dihydrate (Figure 1b). Both hydrogen bond donors (carboxylic acid $\mathrm{OH}$ and $\mathrm{NH}^{+}$) of $\mathrm{BSH}^{+}$and the strong $\mathrm{Cl}^{-}$acceptor participate in hydrogen bonding in all of the structures. In Forms I and II, intermolecular $\mathrm{N}^{+}-\mathrm{H} \cdots \mathrm{Cl}^{-} \cdots \mathrm{H}-$ $\mathrm{O}$ interactions link the $\mathrm{B}^{+} \mathrm{H}^{+}$cations and $\mathrm{Cl}^{-}$anions directly to form $\mathrm{C}_{2}^{1}(8)$ hydrogen bonded chains. Alcohol $-\mathrm{OH}$ groups insert between the carboxylic acid and $\mathrm{Cl}^{-}$anions to form extended $\left(\mathrm{N}^{+}-\mathrm{H} \cdots \mathrm{Cl}^{-} \cdots \mathrm{H}-\mathrm{O}_{\mathrm{S}} \cdots \mathrm{H}-\mathrm{O}\right)$ hydrogen bonded $C_{3}^{2}(10)$ chains in the solvates. The ability of the solvent to bridge one or two carboxylic acid and chloride ion hydrogen bonding pairs appears to determine the solvate stoichiometry among the known $\mathrm{B} 5 \mathrm{HCl}$ alcohol solvates. In contrast to the relatively simple hydrogen bonding of the neat forms and the alcohol solvates, the incorporation of water molecules in the dihydrate leads to an extensive hydrogen bonding layer network, in which the benzisoxazole ring $\mathrm{N} 1$ and carboxylic acid $\mathrm{C}=\mathrm{O}$ of $\mathrm{BSH}^{+}$are also used as acceptors (Figure 5c).

The incorporation of solvent, along with the ea conformation found in both Form II and the dihydrate, produce different hydrogen bonding topologies across the $\mathrm{B} 5 \mathrm{HCl}$ crystal structures, yet the packing of the hydrogen bonded chains in both the neat forms and the alcohol solvates and layers in the dihydrate appears to be driven by a common interaction: $\pi$ stacking of interdigitated $\mathrm{B}^{+} \mathrm{H}^{+}$benzisoxazole rings. For the alcohol solvates, the spacing of $\mathrm{BSH}^{+}$cations in the ee conformation (3.51-3.59 $\AA$ separation), which allows the solvent $\mathrm{OH}$ to insert between the carboxylic acid and chloride ion, produces very stable ribbon (monoalcohol solvate) and layer (dialcohol solvate) motifs, Figure 5. Ring stacking is also seen in the unsolvated structures, though without the solvent molecule, the benzisoxazole groups tilt in Form I to allow for close packing. Likewise, the benzisoxazole rings are tilted in the dihydrate structure, presumably to allow the ring nitrogen to participate in hydrogen bonding and to enable efficient packing of hydrogen bonding building blocks.

In contrast to the dialcohol solvates, where the solvent forms a covalently bound bridge between the ionic layers (Figure 5e), the alkyl groups of the monoalcohols form a hydrocarbon... hydrocarbon van der Waals interface layer. Close packing of the alkyl groups forces adjacent ribbons to be offset in the stacking direction (Figure 5d).

There is much greater diversity to the crystal packing of the $\mathrm{B} 5 \mathrm{HCl}$ alcohol solvates than suggested in Figure 5d,e. The diol hemisolvates, for example, clearly have two-dimensional (2D) similarity, but based on their different crystal symmetry, cannot be isomorphous. In fact, close inspection of the solvate structures along the $\pi$-stacking direction shows that the adjacent $\mathrm{BSH}^{+}$cations are inversion-related in $\mathrm{S}-\mathrm{MeOH}$, 
(a) Form I

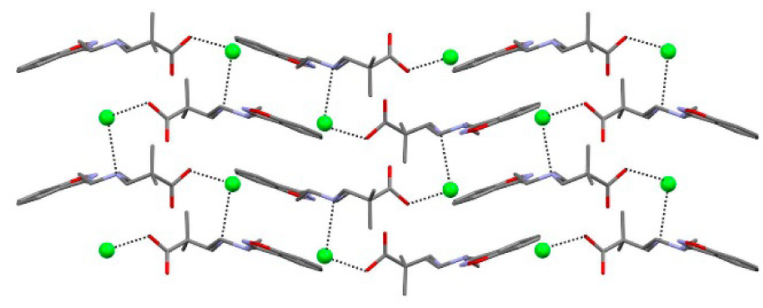

(b) Form II

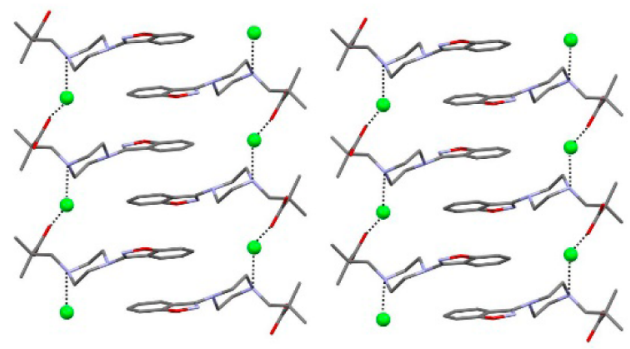

(d) Monoalcohols

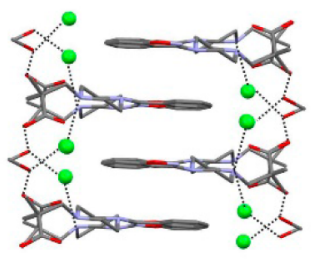

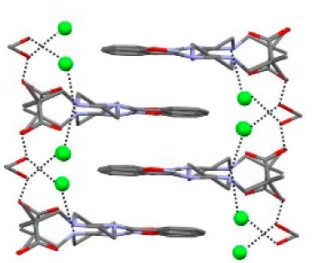

(c) Dihydrate

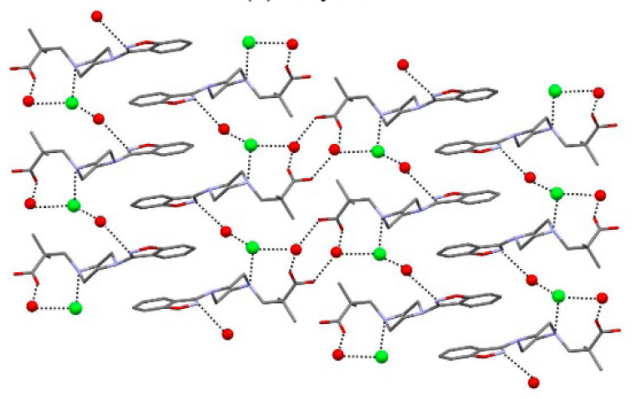

(e) Dialcohols

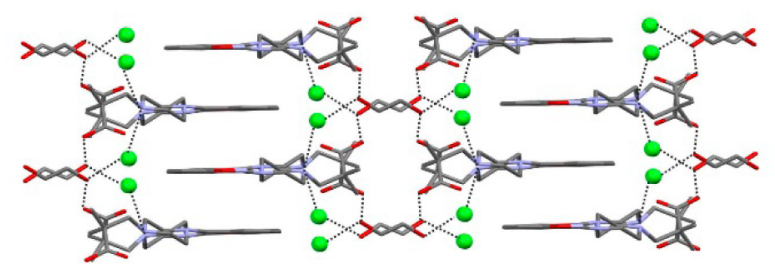

Figure 5. Crystal packing of $\mathrm{B} 5 \mathrm{HCl}$ in (a) Form I, (b) Form II, (c) dihydrate, (d) monoalcohol solvates represented by S-MeOH, and (e) dialcohol solvates represented by S-PrGly, showing interdigitation of benzisoxazole rings from neighboring hydrogen bonding chains/layers. Hydrogen bonds are shown as dotted lines. Hydrogen atoms are omitted for clarity.

whereas they are screw-related in all other solvates, Figure 6. This means that ${\mathrm{B} 5 \mathrm{H}^{+}}^{+}$stacks in $\mathrm{S}-\mathrm{MeOH}$ are uniquely heterochiral, whereas alternating homochiral stacks of $\mathrm{BSH}^{+}$ are seen in all other alcohol solvates. Additionally, the individual $\mathrm{B} \mathrm{H}^{+}$stacks are usually oriented parallel to one another, but they can also be in a herringbone arrangement as seen for the PrGly solvate.

The packing arrangements shown in Figure 6 did not fully account for the diffraction of some of the solvate crystals. Shown in Figure 7 are reciprocal lattice reconstructions from two different crystals of $\mathrm{S}-\mathrm{MeOH}$, one crystal showing clear signs of nonmerohedral twinning along the $(\mathrm{hOl})$ direction (the nonmerohedral twin law corresponds to a $180^{\circ}$ rotation about the crystallographic $a$-axis) and the other showing signs of disorder in the form of diffuse scattering (except for this difference, the two $\mathrm{MeOH}$ solvate structures are perfectly identical). ${ }^{34}$ Although there was some evidence of alternate solvent orientations, suitable models for the electron density in four of the solvates (namely, in the $\mathrm{nBuOH}, \mathrm{iBuOH}, \mathrm{nPeOH}$, and one of the $\mathrm{MeOH}$ solvate structures) were only obtained after modeling the $\mathrm{Cl}^{-}$in a second site. The occupancy of the second $\mathrm{Cl}^{-}$site was generally low and varied from solvate to solvate, ranging from $3 \%$ in the methanol solvate to ca. $6.5 \%$ in the pentanol solvate.

The location of a second $\mathrm{Cl}^{-}$site close to the piperazine ring in three of the four monoalcohol solvates $(\mathrm{MeOH}, \mathrm{iBuOH}$, and $\mathrm{nPeOH}$ ) suggests the presence of an alternate stacking of $\mathrm{B}_{5} \mathrm{H}^{+}$ cations. The atoms in the rest of the molecule, in order to prevent unphysical clashes in these crystal structures, would have to adapt to the minor component positions of the $\mathrm{Cl}^{-}$ion. Unfortunately, the only window into the stacking errors in the $\mathrm{B} 5 \mathrm{HCl}$ solvate single crystals was through the alternate $\mathrm{Cl}^{-}$ positions as the lighter atoms of $\mathrm{BSH}^{+}$could not be seen in the electron density maps at such low occupancy levels. However, on the basis of the observation of diffuse scattering along the $b^{*}$ crystallographic direction in one of the $\mathrm{MeOH}$ solvate crystal structures (Figure $7 \mathrm{~b}$ ), the disorder component is consistent with the alternate packing motif, namely, the homochiral stacking seen in the higher alcohol solvates as an intergrowth in the heterochiral stacking of the $\mathrm{MeOH}$ solvate. Conversely, heterochiral stacks seen in the $\mathrm{MeOH}$ solvate are likely intergrowths in some of the higher alcohol solvate structures. The remarkably similar steric envelope of each stacking arrangement that lends itself to intergrowths is illustrated for the $\mathrm{MeOH}$ solvate in Figure $8 \mathrm{~d}-\mathrm{f}$.

3.3. Construction of Models for the Other Alcohol Solvates. The difficulty in growing solvate single crystals of S$\mathrm{nPrOH}, \mathrm{S}-2 \mathrm{BuOH}$, and $\mathrm{S}-\mathrm{nOcOH}$ required a complementary approach, including PXRD, ssNMR, and lattice energy minimization, to propose structure models. The powder diffraction patterns (Figure 2) of the three solvates suggest that they may be related to the other single-crystal X-ray diffraction (SCXRD) characterized monoalcohol solvates, though the patterns in some cases suffer from marked preferred orientation effects. Indexing of the transmission PXRD data (Table S3) revealed that the monoalcohol solvates have 


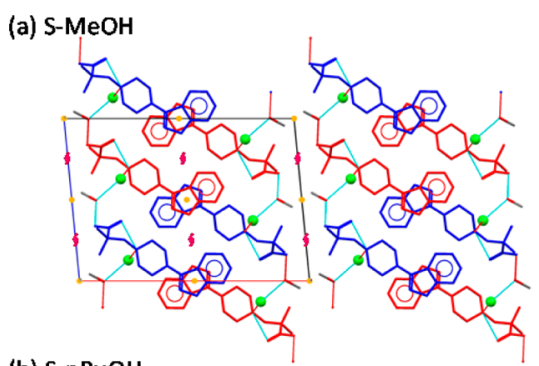

(b) S-nBuOH

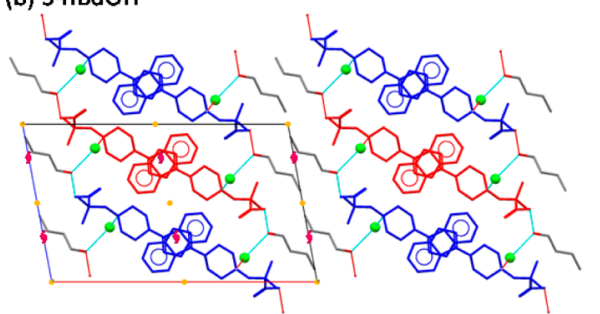

(c) S-PrGly

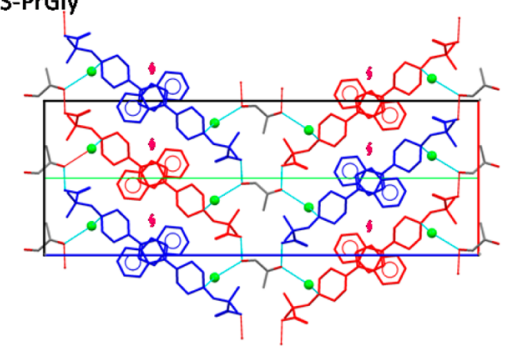

Figure 6. Structural diversity among $\mathrm{B} 5 \mathrm{HCl}$ alcohol solvates is apparent in (a) S-MeOH, (b) S-nBuOH, and (c) S-PrGly, which feature heterochiral and homochiral stacking of $\mathrm{BSH}^{+}$conformational enantiomers (shown in red and blue). In $\mathrm{S}-\mathrm{MeOH}$, neighboring $\mathrm{BSH}^{+}$ cations are uniquely related by inversion centers (orange dots) to form heterochiral stacks that are aligned, whereas in $\mathrm{S}-\mathrm{nBuOH}$, homochiral stacks of screw-related (pink screw axis symbol) $\mathrm{B}^{+} \mathrm{H}^{+}$cations are aligned. By contrast, homochiral stacks of screw-related $\mathrm{BSH}^{+}$cations are uniquely arranged in a herringbone motif in S-PrGly. Only the major $\mathrm{Cl}^{-}$position is shown in (a) and (b).
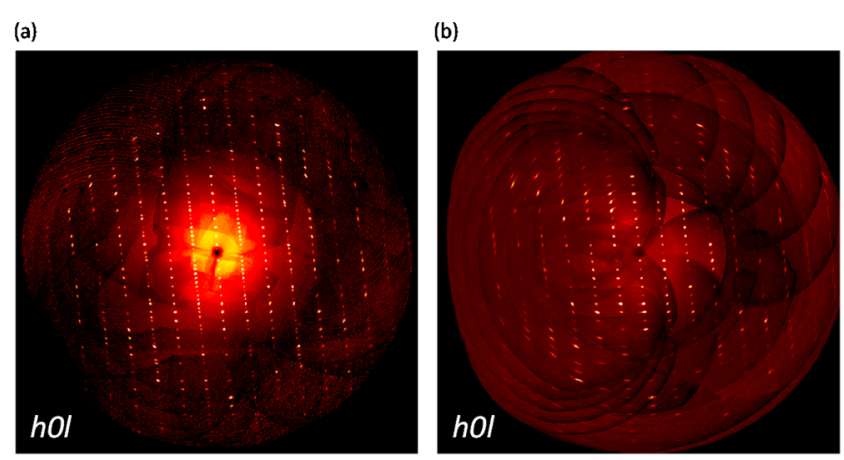

Figure 7. Simulated precession photographs showing the respective (hol) slices through the reciprocal lattices of the two $\mathrm{B} 5 \mathrm{HCl} \mathrm{MeOH}$ solvate structures. Panel (a) shows additional reflections owing to nonmerohedral twinning, but no smeared reflection profiles as a result of $\mathrm{Cl}^{-}$disorder. Panel (b) shows smeared reflections due to $\mathrm{Cl}^{-}$ disorder, but no extra reflections. Except for the circumstance that one of the $\mathrm{MeOH}$ solvate structures shows nonmeroheral twinning and the other $\mathrm{Cl}^{-}$disorder, the two structures are perfectly identical.

monoclinic crystal symmetry and the $P 2_{1} / c$ space group in common, but differ significantly in the length of the $a$ crystallographic axis. The latter varies in proportion to the length of the alcohol hydrocarbon tail. On the basis of each cell volume it could be concluded that only one $\mathrm{B} 5 \mathrm{HCl}$, in agreement with the structures solved from single crystal data, is present in each asymmetric unit $\left(Z^{\prime}=1\right)$. However, based on the indexed cells it is not possible to determine the details of the crystal packing, such as whether homochiral versus heterochiral stacks of ${\mathrm{B} 5 \mathrm{H}^{+}}^{+}$cations or aligned versus herringbone layers, are present. The quality of the crystals and instability of the solvates did not allow us to attempt structure solution from PXRD data.

Apart from Form I impurity peaks, the ssNMR spectra of the alcohol solvates (Figure 3) show one peak for each carbon in $\mathrm{B} \mathrm{H}^{+}$, consistent with the single crystal and powder diffraction data having identified one molecule in each crystallographic asymmetric unit. Remarkably, the spectra are virtually identical between 100 and 190 ppm, the region in which benzisoxazole ring and dimethylpropanoic acid carbonyl carbons appear. The strikingly similar electronic environments of the benzisoxazole ring carbons in the alcohol solvates are not surprising given that these solvates were shown by X-ray crystallography to form very similar layers held together by $\pi$-stacking of interdigitated benzisoxazole rings (Section 3.2). Likewise, the nearly identical chemical shifts of the carboxylic acid carbon atoms are consistent with their similar hydrogen-bonding environments across the family of solvates. S-nPrOH, S- $2 \mathrm{BuOH}$, and S$\mathrm{nOcOH}$, in producing the same signature ssNMR peaks as the other alcohol solvates between 100 and $190 \mathrm{ppm}$, appear to be based on the common layers self-assembled by $\pi$-stacking of neighboring benzisoxazole rings with the dimethylpropionic acid group $\mathrm{H}$-bonded to the alcohol solvents. As with PXRD, we were unable to determine by ssNMR spectroscopy whether homochiral or heterochiral stacks of $\mathrm{BSH}^{+}$cations (Figure 8) were present in the three solvates; the two stacking arrangements gave comparable calculated ${ }^{13} \mathrm{C}$ shielding constants (Figure S45). We were also unable to deduce by ssNMR spectroscopy the long-range aligned or herringbone stacking orientation in these solvates. The experimental ssNMR peak positions did, however, give clear evidence for solvent disorder for S-nPrOH, S-2BuOH, and S-nPeOH (Supporting Information, Section 7). In cases of incidental peak overlap, we cannot rule out other monoalcohol solvates being similarly disordered.

From the PXRD patterns and room temperature cell parameters (Table S3) of the "uncharacterized" solvates and available single crystal data of isostructural forms, we were able to propose ordered B5HCl-HOR models for the alcohol solvates (assuming a parallel (versus herringbone) arrangement of $\mathrm{BSH}^{+}$stacks), allowing variations in the positioning of the alcohol hydrocarbon tails and homochiral/heterochiral stacks of $\mathrm{BSH}^{+}$cations. For S-EtOH, S-nBuOH, S-iBuOH, and S$\mathrm{nPrOH}$, the four structures for which modeling was performed prior to solving the structures from SCXRD data, the dominant experimental packing arrangement (heterochiral $\mathrm{BSH}^{+}$stacks) and solvent orientation(s) were correctly calculated as the lowest in lattice energy. Similarly, for S-MeOH and S-iPrOH, the two monoalcohol structures known prior to starting the modeling of the $\mathrm{B} 5 \mathrm{HCl}$ solvates, the calculations revealed that for $\mathrm{S}-\mathrm{MeOH}$ the heterochiral and for $\mathrm{S}-\mathrm{iPrOH}$ the homochiral

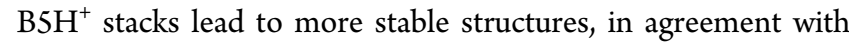
the dominant packing arrangements seen from SCXRD determinations. For both $\mathrm{S}-\mathrm{nPrOH}$ and $\mathrm{S}-2 \mathrm{BuOH}, 12$ different models were generated and the evaluation of lattice energies revealed that alternative solvent orientations and homochiral/ heterochiral $\mathrm{BSH}^{+}$stacks are close in energy, suggesting solvent 

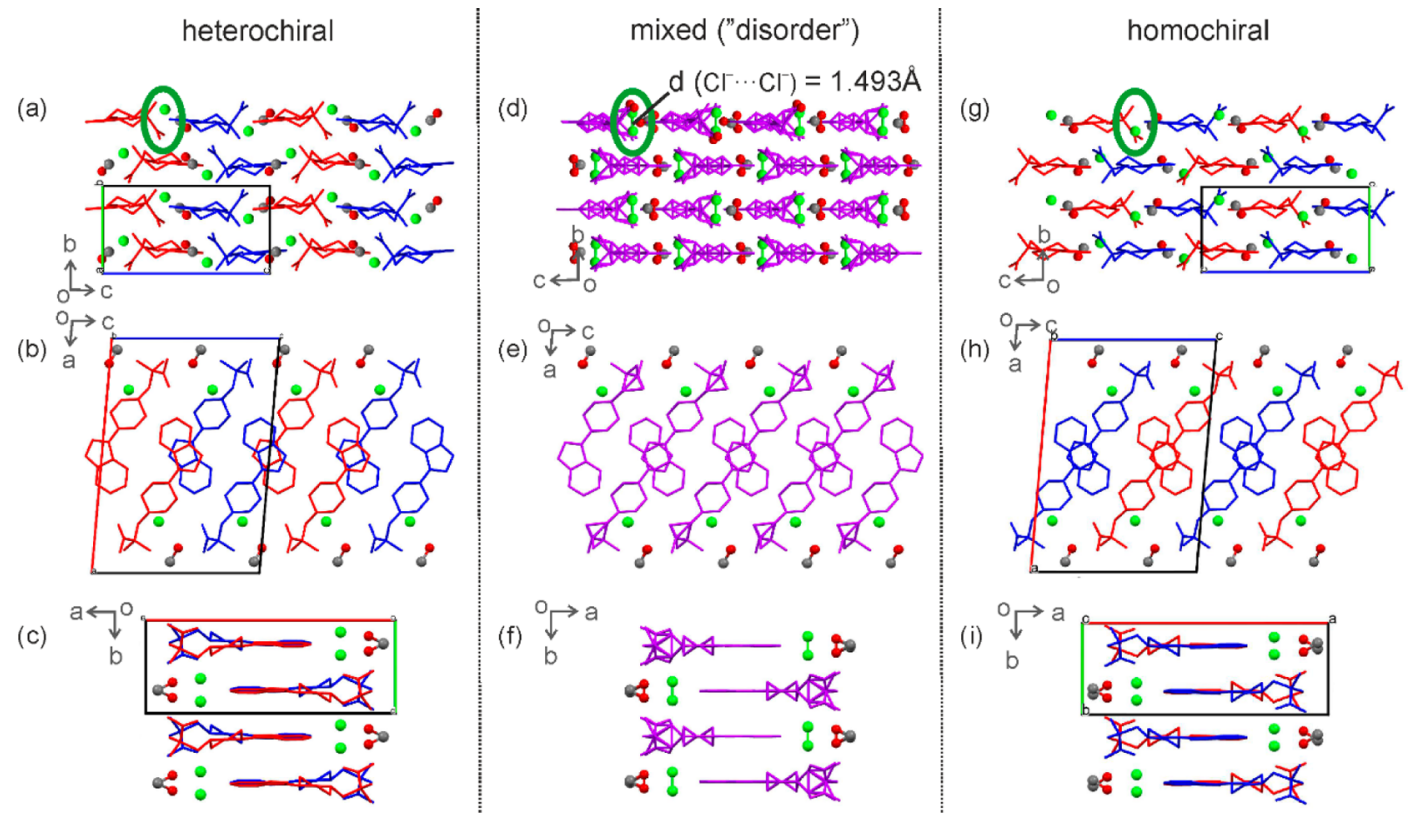

Figure 8. Comparison of possible methanol solvate packings: $(\mathrm{a}-\mathrm{c})$ heterochiral stacks of $\mathrm{B} \mathrm{H}^{+}$cations, $(\mathrm{g}-\mathrm{i})$ homochiral $\mathrm{B} 5 \mathrm{H}^{+}$stacks, and $(\mathrm{d}-\mathrm{f})$ mixed heterochiral and homochiral stacks. Color scheme of $\mathrm{B}^{2} \mathrm{H}^{+}$cations defines whether the $\mathrm{B}^{2} \mathrm{H}^{+}$stacks are heterochiral $(\mathrm{b})$, homochiral $(\mathrm{h})$, or mixed (e). Green ovals depict alternate $\mathrm{Cl}^{-}$positions. Models of the possible methanol solvate packings were constructed with heterochiral, homochiral, and mixed hetero-/homochiral stacking arrangements (Figures S19 and S20), keeping the lattice parameters constant during structure optimization. The mixed hetero-/homochiral stacking arrangement was checked for higher symmetry using PLATON and resulted in the $\mathrm{Cl}^{-}$and ${\mathrm{B} 5 \mathrm{H}^{+}}^{+}$disorder seen in $\mathrm{d}-\mathrm{f}$.

and stacking disorder are likely (Figures S34 and S35). Because of the size and flexibility of $n$-octanol, only two S-nOcOH models were generated with the extended solvent conformation and either the homochiral or heterochiral stacks of $\mathrm{BSH}^{+}$ cations. The calculations reveal that stacking disorder is also feasible for this solvate (Supporting Information, section 5.4.8). Thus, for the three solvates not characterized by SCXRD, we are able to provide reasonable crystal structure models (Supporting Information, sections 5.4.6-5.4.8) that are consistent with the available PXRD and ssNMR data, but which cannot confirm the stacking (homo- versus heterochiral) or HOR hydrocarbon orientations that are present. Only SCXRD data can provide the three-dimensional structures, and even this would need careful analysis for disorder in the stacking and alcohol hydrocarbon tail positions.

3.4. Crystal Structure Prediction of $\mathrm{B} 5 \mathrm{HCl}$. The crystal structure prediction search showed that there are many ways of packing the $\mathrm{BSH}^{+}$cation with a chloride ion that are close in energy, containing either observed piperazine ring conformation ( $e a$ and $e e$ ), though the flatter ee conformation tends to produce more densely packed structures (Figure 9). All of the low energy structures are based on $\mathrm{NH}^{+}$and $\mathrm{COOH}$ hydrogen bonding to $\mathrm{Cl}^{-}$, whose five- or six-fold coordination by cations is completed by hydrogens from the aromatic $\mathrm{CH}$ of the benzisoxazole group, $\mathrm{CH}$ on the piperazine ring, and sometimes the $\mathrm{CH}$ from the propionic acid. Two different cations provide the $-\mathrm{NH}^{+}$and $-\mathrm{COOH}$ hydrogen bond donors to one chloride ion, and the cation with the $\mathrm{N}-\mathrm{H}^{+}$ hydrogen bonded to a $\mathrm{Cl}^{-}$usually also has a $\mathrm{Cl}^{-} \ldots \mathrm{H}-\mathrm{C}$ close contact (see Supporting Information, Section 4.2). Form I and most of the computational desolvates are found within $15 \mathrm{~kJ}$ $\mathrm{mol}^{-1}$, i.e., differ by less than $2.5 \%$ of the total lattice energy (Figure 9). The Form I structure is found (as ee568) quite close to the global minimum, within $0.3-1.9 \%$ of its lattice energy,

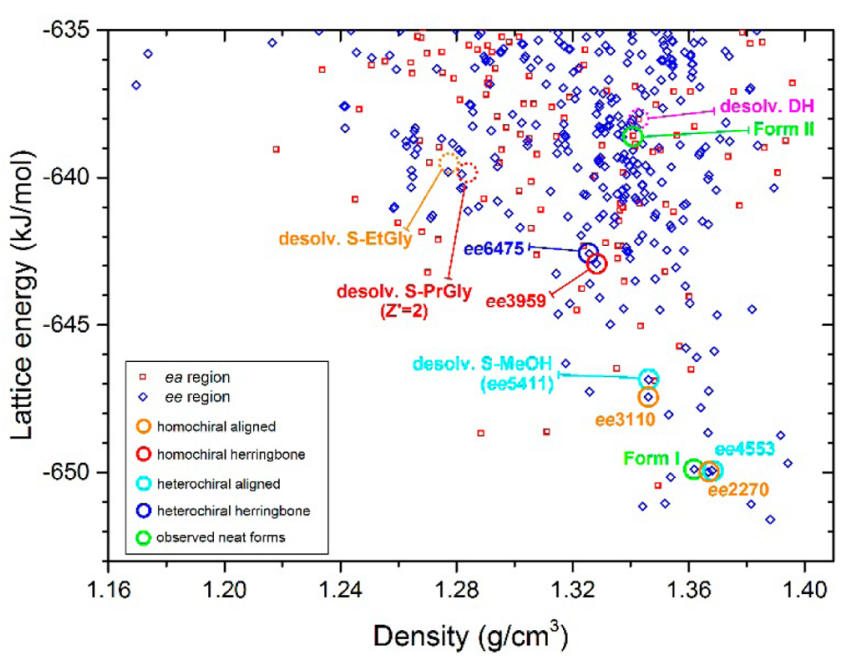

Figure 9. Summary of the crystal structure prediction for $\mathrm{B} 5 \mathrm{HCl}$, with each symbol denoting a crystal structure by its lattice energy and density. The computational desolvates are shown as dotted circles, except that of S-EtOH which is higher in energy (see Table S3). The lowest energy structures found with the same type of packing of the alcohol solvates (as illustrated in Figure 6 above) are encircled in the corresponding color to the solvate label. Green circles label experimentally observed $\mathrm{B} 5 \mathrm{HCl}$ neat forms.

depending on the model for the intermolecular interactions (see Supporting Information, Section 3.5). Form II is found (as ea209) close in energy to the computationally desolvated dihydrate, both being significantly less stable than Form I or the most stable structures with the ea conformation. This emphasizes how desolvation can provide a unique pathway to metastable polymorphs. 
The search also found lower energy structures with the solvate $\mathrm{B} 5 \mathrm{HCl}$ packings among many other variants on the packing of the ions. The structures within just $6 \mathrm{~kJ} \mathrm{~mol}^{-1}$ of the most stable (Figure 10) are analyzed in detail (Table S5), with

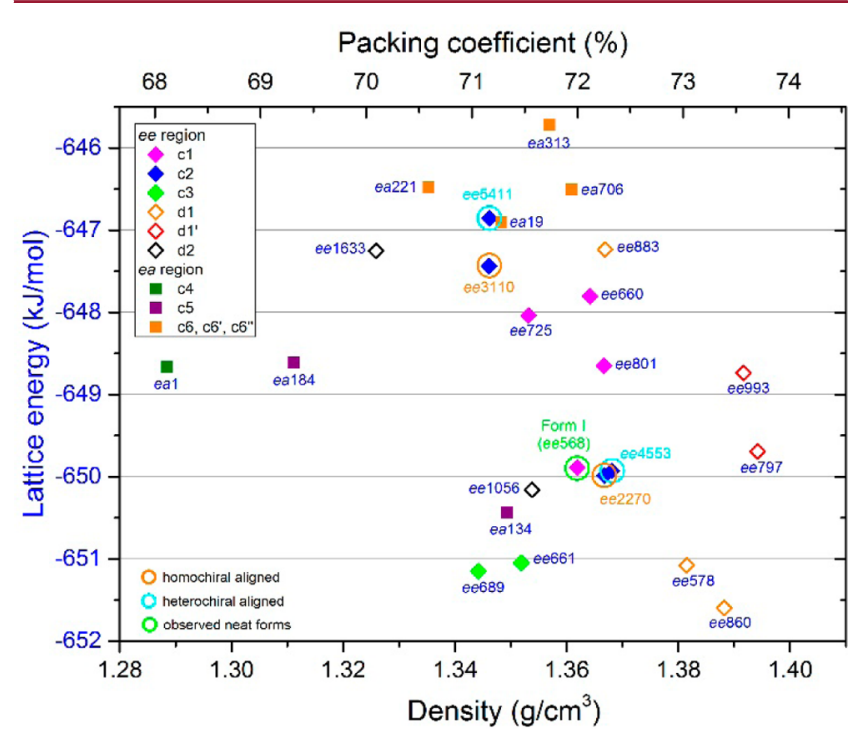

Figure 10. Lower energy region of the CSP study of $\mathrm{B} 5 \mathrm{HCl}$ in Figure 9. The lowest energy structures are labeled by piperazine ring conformation ( $e a$ or $e e$ ) and their energy ranking after the CrystalPredictor search, with the symbols representing the structural classification shown in Figure S7 for ee and Figure S8 for ea. The encircled structures have a similar $\mathrm{B} 5 \mathrm{HCl}$ packing as in the solvates. Green circles label experimentally observed $\mathrm{B} 5 \mathrm{HCl}$ neat forms.

the XPac packing relationships among the ee and ea conformations in Supporting Information, Figures S7 and S8. When the piperazine is in the ee conformation, it and the benzisoxazole group protrude to produce a wide variety of sheet-like structures (Figure S7) with just those seen in the solvate structures illustrated in Figure 11. The thermodynamically competitive ee structures show a range of similar layer-like stackings of the benzisoxazole groups despite differences in the conformation of the propionic acid tail and $\mathrm{Cl}^{-}$interactions (Figure S7).

It is notable that the XPac analysis (Figures S7 and S8) shows a $2 \mathrm{D}$ similarity between the cation packing in the alcohol solvates and low energy structures generated in the search for neat crystal forms (Figure 11): structure ee4553 has the heterochiral aligned double layer of the methanol solvate (Figure 6a); structure ee2270 has the same homochiral double layer aligned construct as the higher monoalcohol solvates (S$\mathrm{nBuOH}$ in Figure $6 \mathrm{~b})$. Both of the computed structures (ee2270 and ee4553) have virtually the same energy as Form I (ee568 in Figure 10). This suggests that the packing arrangement of $\mathrm{BSH}^{+}$in the solvates is energetically competitive with Form I, but more expensive DFT-D calculations predict that these structures are less stable than Form I by up to $3 \%$ of the lattice energy (calculated from Table S8) and comparable in stability to Form II. The herringbone packing of S-PrGly is also less stable, with the lowest energy homochiral (ee3959) and heterochiral (ee6475) packings being similar to one another in energy (Figure 9). The observation of the varied $\mathrm{B}_{5} \mathrm{H}^{+}$packings in the solvates clearly underscores the significant role that different alcohols play in stabilizing and directing the packing of $\mathrm{B} 5 \mathrm{HCl}$ bilayers.

CSP shows that the structure of Form I and the $\mathrm{B} 5 \mathrm{HCl}$ arrangement in the alcohol solvates are among the most stable packings, and the $\mathrm{B} 5 \mathrm{HCl}$ structures that are competitive within likely computational error are either grossly similar in being layer-like structures or contain the ea conformation as in the dihydrate. There appear to be many possible compensating changes in detailed conformation and hydrogen bonding within the layers that could lead to differences in stacking of the layers (Figure 6 and Figure S7). Nonetheless, in showing that no grossly different cation packings are clearly more stable than those observed, the CSP supports the completeness of the experimental search for neat crystal forms. It warns, however, that there could be subtle changes in conformation, hydrogen bonding, or stacking that might only be shown from detailed SCXRD or very high quality PXRD data, and suggests a high probability of variable disorder within different crystallization products.

3.5. Structure-Stability Relationships. Our ability to confirm such a large family of structurally related alcohol solvates for $\mathrm{B} 5 \mathrm{HCl}$ was dictated by both the propensity of the various solvate crystals to nucleate and grow and their stability (or lack thereof) relative to Form I in suspensions and in the solid state. The most stable solvates, S-EtGly, S-PrGly, and S$\mathrm{MeOH}$, not only crystallized with ease from solution, but as each was the thermodynamically stable form in suspensions of the respective alcohols, these solvates could just as easily be obtained by slurry methods and were stable in the solid state as dry powders. By contrast, the solvates of the larger monoalcohols were less stable than Form I in their respective alcohol solutions and therefore crystallized as kinetic forms. Under the right conditions, these solvates could be selectively crystallized, but some were so unstable outside of their mother

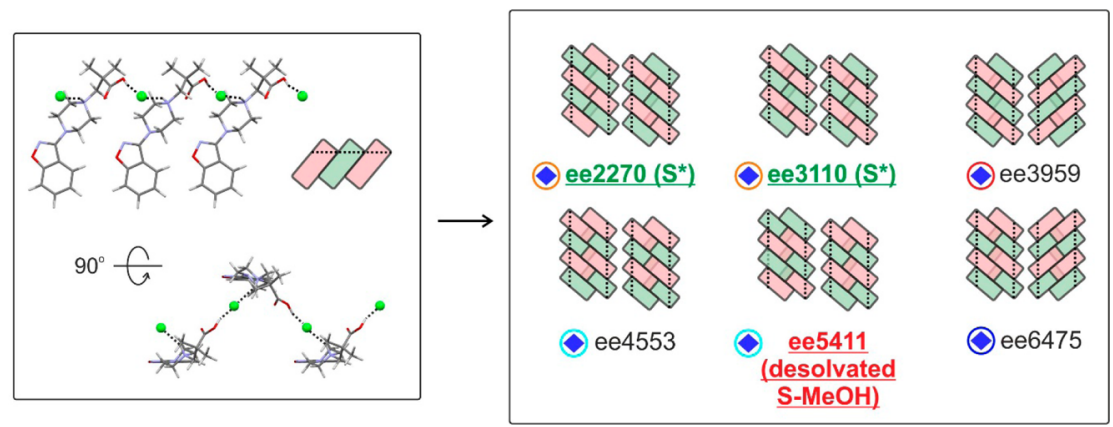

Figure 11. Excerpt from the XPac analysis (Figure S7) of the low energy structural types for the c2 ee conformation, showing the relationship between the double layers in the solvates and their computational desolvates. $\mathrm{S}^{*}$ indicates $2 \mathrm{D}$ packing similarity with all solvates except S-MeOH. 
liquors that rather than harvesting the crystals, they were characterized in wet cakes before conversion to Form I could take place. This strategy was successful for collecting transmission PXRD patterns of the solvates (Figure $2 \mathrm{~b}$ ); however, conversion of some of the more labile solvates $(\mathrm{S}-2 \mathrm{BuOH}, \mathrm{S}$ $\mathrm{nPeOH}, \mathrm{S}-\mathrm{nPrOH}$ ) to Form I could not be altogether avoided during ssNMR analysis (Figure 3 ).

On a molecular level, solvate formation was driven not only by the formation of stable hydrogen bonding ribbons/bilayers between $\mathrm{B} 5 \mathrm{HCl}$ and the solvent (Figure $5 \mathrm{~d}, \mathrm{e}$ ), but also weaker interactions which contribute to the overall crystal packing efficiency. As shown in Figure 12, the packing coefficients of all

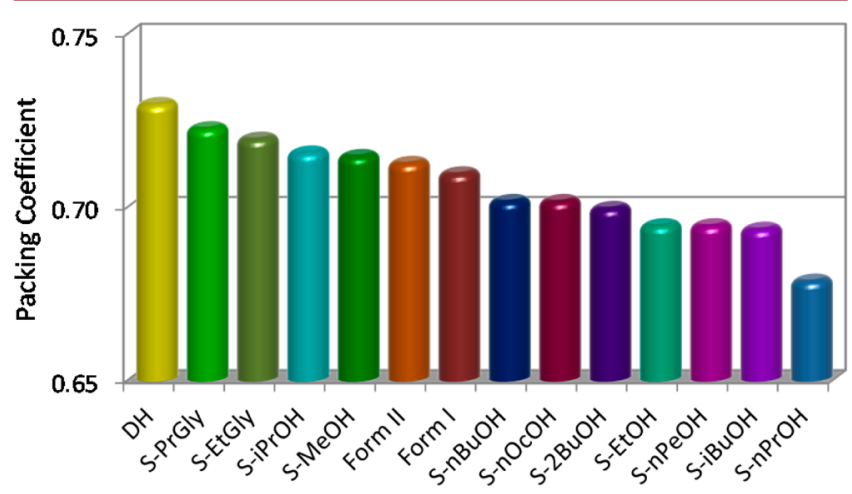

Figure 12. Packing coefficients of the $\mathrm{B} 5 \mathrm{HCl}$ solid forms at $\mathrm{RT}$, comparing the fraction of space occupied by atoms in the crystal structures.

of the $\mathrm{B} 5 \mathrm{HCl}$ structures span much of the commonly observed range $(65-75 \%)$ for organic crystals, and there is significant variation among the monoalcohol solvates. Interestingly, Form I falls toward the middle of the $\mathrm{B} 5 \mathrm{HCl}$ packing efficiency spectrum. It is noteworthy that the crystallizability of the monoalcohol solvates as thermodynamic or kinetic forms generally tracked with the packing coefficients, with the most challenging solvates to crystallize, harvest, and preserve being those with the poorest crystal packing.

The thermal stability and desolvation pathways of freshly crystallized $\mathrm{B} 5 \mathrm{HCl}$ dihydrate and solvates were evaluated by a combination of isothermal annealing (Table S27), differential thermal analysis (Figure S57), and gravimetric vapor sorption (GVS) analysis (Figures S59 and S60). The dihydrate was shown to be the least thermally stable form, with the waters of crystallization lost at room temperature at sufficiently low $\mathrm{RH}$ (e.g., $\mathrm{N}_{2}$ purge). By carefully adjusting the drying temperature, it was possible to produce either Form I or Form II on dehydration, with Form II being obtained in phase pure form only on drying at room temperature. Higher drying temperatures yielded mixtures of the two polymorphs or phase pure Form I. On standing at low $\mathrm{RH}$, the mixtures transformed within a day to the thermodynamically most stable polymorph, Form I.

DSC thermograms of Forms I and II were measured at heating rates ranging from 10 to $300{ }^{\circ} \mathrm{C} \mathrm{min}^{-1}$. At the comparatively slower heating rates $\left(10,50\right.$, and $\left.100{ }^{\circ} \mathrm{C} \mathrm{min}^{-1}\right)$, Form II underwent an exothermal event at temperatures ranging from 90 to $150{ }^{\circ} \mathrm{C}$, depending on the heating rate and sample pretreatment (grinding), Figure 13. This transition, with a measured enthalpy of $-8.5 \pm 0.2 \mathrm{~kJ} \mathrm{~mol}^{-1}$, was shown by PXRD to be the transformation of Form II to Form I. No visual signs of melting were observed over this temperature range by

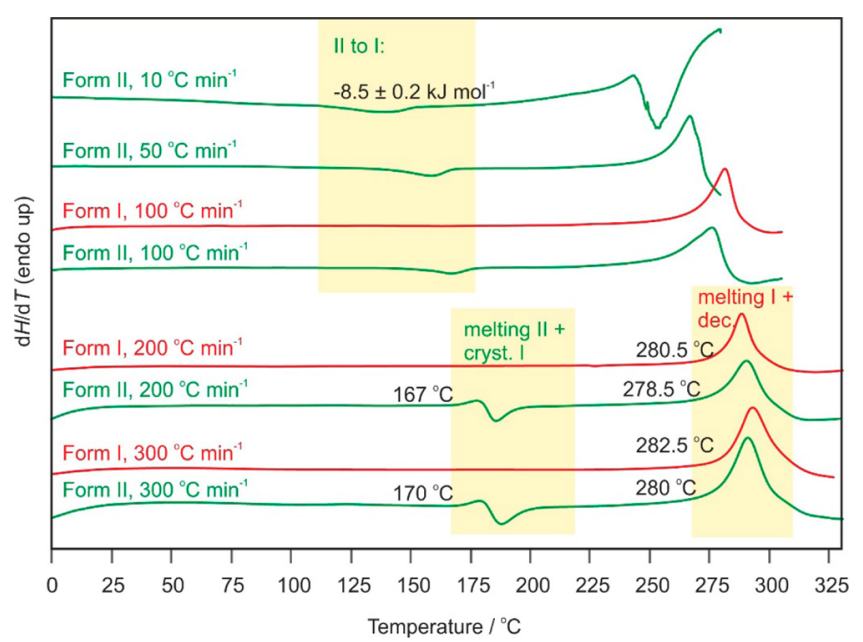

Figure 13. DSC thermograms of $\mathrm{B} 5 \mathrm{HCl}$ anhydrate polymorphs in the temperature range from 0 to $325{ }^{\circ} \mathrm{C}$, measured at heating rates spanning 10 to $300{ }^{\circ} \mathrm{C} \mathrm{min}^{-1}$. cryst. - crystallization, dec decomposition.

hot stage microscopy. Upon further heating, Form I decomposes with no clear indication of its melting temperature $\left(>250{ }^{\circ} \mathrm{C}\right)$. However, applying faster heating rates $\left(\geq 200{ }^{\circ} \mathrm{C}\right.$ $\mathrm{min}^{-1}$ ) allowed us to measure the melting of both polymorphs. Form II melts at approximately $167{ }^{\circ} \mathrm{C}$ (endothermic peak), followed almost immediately by a fast (exothermic) recrystallization of Form I. Form I melting was observed at approximately $280{ }^{\circ} \mathrm{C}$, which is significantly higher in temperature than the Form II melting point. This large melting point difference means that when Form II approaches the melting point, its free energy is greatly in excess of Form I. As a result, the system is driven to undergo both melting and direct solid-state conversion to Form I; which transition actually happens will depend on sample-specific properties, e.g., crystal perfection, particle size, impurities, etc. Importantly, the higher melting point of Form I, the exothermic transition from Form II to Form I, the observed conversion of Form II to Form I at room temperature and lattice energy estimations, which have Form I as distinctively more stable than Form II at $0 \mathrm{~K}$ (Table S8), collectively point to Form I being monotropically more stable than Form II.

In contrast to the dehydration, the desolvation of the organic solvates required more thermal energy, and not surprisingly, the temperature conditions at which desolvation was observed for the monoalcohol solvates were generally milder $\left(25^{\circ} \mathrm{C}\right.$ lower $)$ than for S-EtGly and S-PrGly, where each solvent is bound by twice the number of hydrogen bonds. Within the series of monoalcohol solvates, desolvation was consistently observed near $100{ }^{\circ} \mathrm{C}$, despite all of the solvents between the $\mathrm{B} 5 \mathrm{HCl}$ layers, except methanol, being exposed in one or more directions to the atmosphere (Figure 14). As there is seemingly little obstructing most of the solvents from evacuating the solvate crystal structures, desolvation temperatures might have been expected to track with solvent volatility. Instead, the alcohols are lost at a similar temperature, which for the smaller ones in the series is well above their boiling points. That is, desolvation occurs when a comparable amount of activation energy is provided, i.e., enough to break the similar $\mathrm{Cl}^{-} \ldots \mathrm{H}-$ $\mathrm{O}_{\mathrm{S}} \cdots \mathrm{H}-\mathrm{O}$ interactions found in all of the crystal structures.

Gravimetric moisture sorption/desorption (GVS) analysis was used to assess the $\mathrm{RH}$ stability of all of the $\mathrm{B} 5 \mathrm{HCl}$ solid 

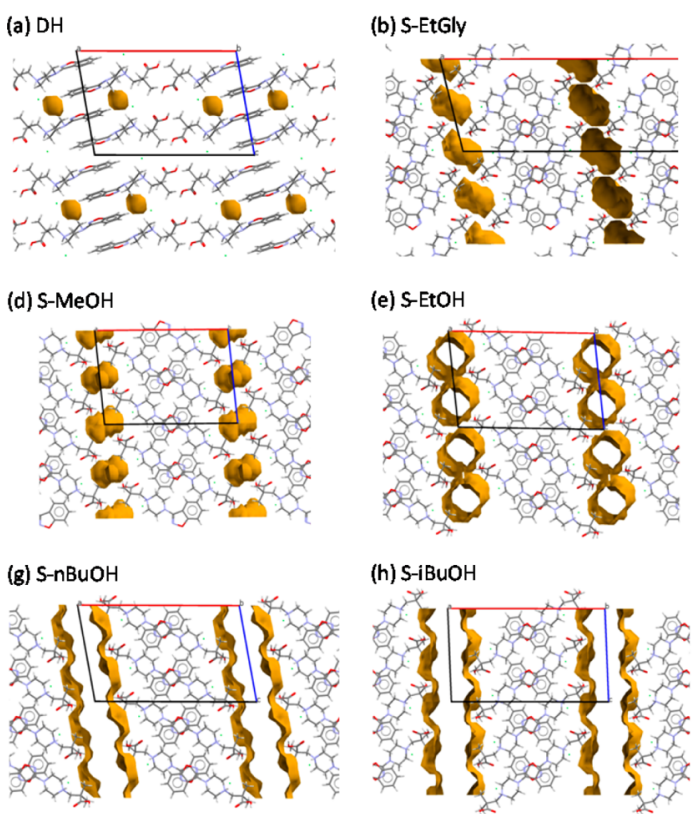

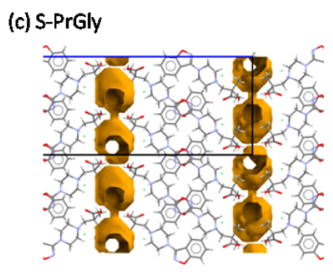

(f) S-iPrOH
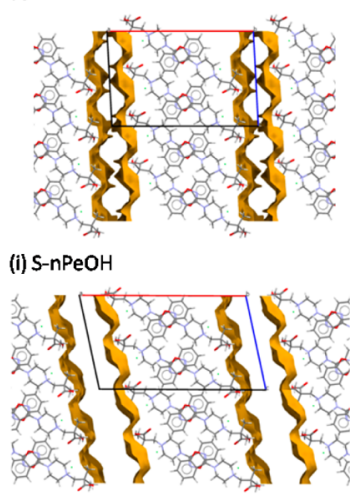

Figure 14. (a-i) Crystal packing of $\mathrm{B} 5 \mathrm{HCl}$ solvates at $100 \mathrm{~K}$ (except S-PrGly, which is shown at $\mathrm{RT}$ ), contrasting void spaces occupied by the solvents of crystallization. Void space was calculated using Mercury (CFC Version 3.9) with the orange surface showing the closest contact possible for a solvent atom of default probe radius $(1.2 \AA)$.

forms at room temperature (Supporting Information, section 14). Whereas highly crystalline, phase pure samples of Form I and the dihydrate showed minimal water vapor uptake (or loss) over the $\mathrm{RH}$ range 5-95\% (Figure S59), at low $\mathrm{RH}(<5 \%)$ the dihydrate loses its water of crystallization and converts to Form II, a process which is reversed above about 10\% RH (Figure S60). In contrast, the alcohol solvates in most cases experienced a sharp weight loss on increasing the $\mathrm{RH}$ to above 50-60\%. The dramatic weight change was ascribed to the loss of solvent as neat Form I crystallized. While the $\mathrm{RH}$ condition at which each phase transformation was first noted was relatively constant across the solvates, the rate and extent of conversion above this $\mathrm{RH}$ could not be deduced from the gravimetric data in all cases owing to the low volatility of some of the solvents. Nonetheless, the GVS data show that water, in even catalytic quantities, accelerates the conversion of the $\mathrm{B} 5 \mathrm{HCl}$ solvates to Form I, which given the gross structural differences between the neat and solvated forms is presumed to occur through a reconstructive mechanism. Here as the $\mathrm{RH}$ is increased, a supersaturated (with respect to Form I) water layer presumably forms at the solid surface partially dissolving the water-soluble $\mathrm{B} 5 \mathrm{HCl}$ solvate, which is likely to provide the thermodynamic driving force for nucleation and growth of the more stable, less soluble Form I.

\section{DISCUSSION}

4.1. Overall Molecular Picture of Solid Form Landscape of $\mathrm{B} 5 \mathrm{HCl}$. Solid form screens in pharmaceutical development aim to find the stable crystal form that is most likely to be developed for the drug product, along with any forms that could conceivably appear during processing or longterm storage. ${ }^{35}$ Late appearing solid forms could eventually become the phase used to deliver the drug, ${ }^{36}$ and so drug development is far more efficient if all solid forms can be established early on. This means that any hint or sign of a new crystal form during solid form screening (or development of the crystallization process) should be promptly followed up on to determine its pharmaceutical relevance. Although detailed crystal structure analysis undoubtedly adds assurance to the screening output, it is not usually needed to merely establish the existence of forms comprising a solid form landscape. B5HCl Forms I and II, dihydrate and the dialcohol solvates, for example, were rather straightforward to distinguish by routine PXRD. However, the majority of $\mathrm{B} 5 \mathrm{HCl}$ solid forms, all of which were later shown to be monoalcohol solvates, could not be confirmed solely by the (100), (200), and (300) diffraction peaks in their PXRD patterns (Figure $2 \mathrm{a}$ ).

The interpretation of the reflection PXRD patterns (Figure 2a) was clearly complicated by preferred orientation effects, and to our surprise, gentle grinding of the samples failed to alleviate the problem. In hindsight, the platy solvate crystals, which at the time were thought to be too thin, were very likely plagued by "packing problems" that may have been partially corrected on scale up using the optimized (slower) crystallization conditions. Ultimately, higher quality samples of these $\mathrm{B} 5 \mathrm{HCl}$ solvates could be distinguished from one another using transmission PXRD (Figure 2b) and solid-state NMR spectroscopy (Figure 3), although neither of these techniques was sufficient for characterizing crystal growth errors (disorder, intergrowths) or ruling out packing polymorphs. Indeed, the disorder only showed up in the single crystals due to the high unassigned electron density associated with the $\mathrm{Cl}^{-}$and the care taken to get reasonably good models of the diffraction data. ${ }^{37}$ The CSP and solvate structure calculations helped give confidence in what emerged as the molecular level view of $\mathrm{B} 5 \mathrm{HCl}$ crystallization behavior.

4.1.1. Why so Many Forms? B5HCl, like most pharmaceuticals, ${ }^{38}$ crystallizes in multiple forms, solvated and nonsolvated. This $\mathrm{HCl}$ salt is unusual, however, in how it is able to form such a large family of structurally related solvates (Supporting Information, section E). Rather than forming an open threedimensional framework with voids that can be stabilized by inclusion of a variety of solvent molecules, ${ }^{7 \mathrm{a}} \mathrm{B} 5 \mathrm{HCl}$ specifically binds water or alcohols, and in all solved crystal structures and 
(a)
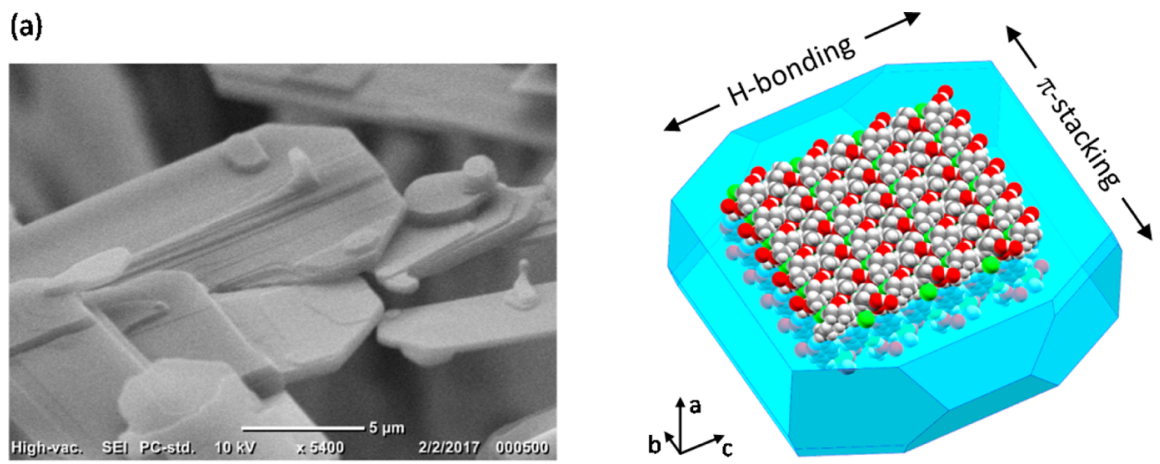

(b)
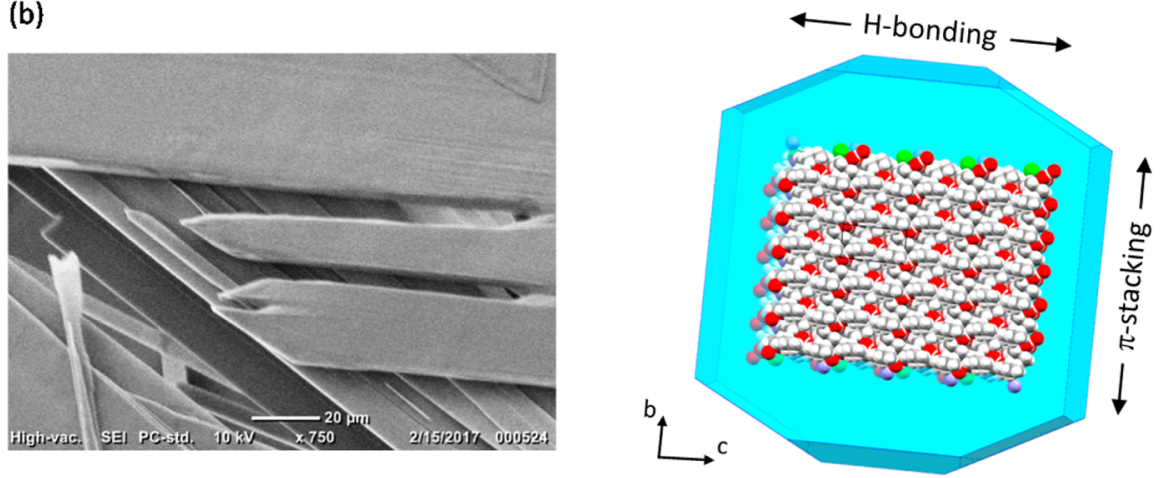

Figure 15. SEM image and BFDH morphology of platy (a) S-MeOH and (b) S-nBuOH crystals, showing layering of the morphologically dominant (100) face, which on a molecular level is decorated with hydrocarbon tails of the solvent.

the majority of computer generated low energy packings, layer structures are formed. Within the layers there is an alternation of interdigitated benzisoxazole rings and hydrogen bonding chains or dimers involving the $\mathrm{Cl}^{-}$and $\mathrm{N}^{+} \mathrm{H} / \mathrm{COOH}$ groups of

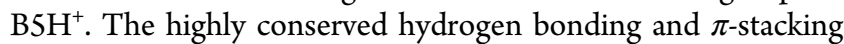
observed for the solvates reflect the strength of binding within the $\mathrm{B} 5 \mathrm{HCl}$ layers, where water or alcohol hydroxyl groups bridge across the cation $-\mathrm{Cl}^{-}$interactions in arrangements that are reinforced by benzisoxazole ring stacking (Figure 5).

The addition of the solvent $\mathrm{OH}$ group to the coordination sphere of the $\mathrm{Cl}^{-}$appears to give a range of alcohol solvates that are (at least in their mother liquor) competitive in energy to Form I. Although $\mathrm{OH}$ coordination of the $\mathrm{Cl}^{-}$can be thermodynamically stabilizing, metastable solvates may form simply because the crystals assemble while a solvent molecule is still coordinating the $\mathrm{Cl}^{-}$- the balance is very dependent on the packing of the rest of the molecules/ions. Since the ionic forces are so strong and compared to other intermolecular forces long-range, small changes in distances between $\mathrm{Cl}^{-}$ions and polar protons will have a large effect on the energy. The energy will also be sensitive to density and packing efficiency through dispersion forces, along with conformation change energies, hydrogen-bonding, $\pi \cdots \pi$ stacking, and other terms. Interestingly, modeling an isostructural monohydrate (Supporting Information, section 5.4.10) based on either the homochiral or heterochiral stacking arrangement of the solvates gave structures that were significantly less stable than Form I or the dihydrate. This emphasizes that the alcohol hydrocarbon layer, the weakest and most variable part of the observed solid forms, also plays a significant role in stabilizing the solvate structures.

Which alcohols form solvates with $\mathrm{B} 5 \mathrm{HCl}$ appears to be ultimately determined by the ability of their hydrocarbon tails to close pack between the hydrogen-bonded ribbons/layers. In this respect, $\mathrm{B} 5 \mathrm{HCl}$ is rather accommodating. The layers themselves not only adapt to the solvent by forming homochiral or heterochiral stacks of benzisoxazole rings, but close packing is also achieved as either aligned or herringbone arrangements of the layers (Figure 6) separate and shift to make room for the solvent (Figure 14). For their part, the solvents also adjust to the available space, in many cases finding more than one orientation in the solvate crystal structure. That such a wide range of alcohols can be accommodated between the $\mathrm{B} 5 \mathrm{HCl}$ layers suggests that long-range ionic attractions between the layers may also help stabilize the larger, less well (more weakly) packed, hydrocarbon solvent layers.

4.1.2. Why so Few Forms? One of the most unsettling aspects of experimental solid form screening is not knowing whether important forms, particularly that which is the thermodynamically most stable, have been missed. Certainly the $\mathrm{B} 5 \mathrm{HCl}$ screen was not exhaustive from a methodology perspective, as none of the unusual techniques, including those that have been used to find CSP-predicted polymorphs, such as crystallization under pressure ${ }^{39}$ or templating with structurally related crystals, ${ }^{40}$ were employed. Considering the significant constraints imposed on the $\mathrm{B} 5 \mathrm{HCl}$ solid form screen by its limited solubility and chemical instability, an experienced practitioner would likewise find the diversity of conditions explored using the conventional methodologies to be incomplete at best. Some effort in optimizing crystallization conditions from alcohols had greatly increased the number of forms (solvates) from the few that dropped out of those solvents early in the screen. It is thus fair to ask what thermodynamically feasible forms still await finding appropriate experimental conditions to realize them for the first time.

The structural diversity seen among the known $\mathrm{B} 5 \mathrm{HCl}$ crystal forms most certainly raises the question as to whether 
there are likely to be more forms on the solid form landscape than shown in Figure 4. Solvates from other alcohols, such as isopentyl alcohol and cyclohexanol (for which there is some experimental evidence) seem likely, but what about alternate packings involving heterochiral v. homochiral stacks, aligned v. herringbone layers or different solvent orientations from the alcohols already appearing on the solid form landscape? Could there be energetically competitive polymorphs involving identical layers simply packed in different ways (cf. tazofelone $\left.{ }^{41}\right)$ ? Computational modeling has shown that some structures based on homochiral and heterochiral stacking (e.g., the methanol solvate in Figure 8) are very close in lattice energy, as are structures with different solvent orientations from those observed by SCXRD (Supporting Information). That simulated PXRD patterns and ssNMR spectra of the alternative crystal packing models were virtually indistinguishable means that we cannot rule out the possibility of other forms having crystallized, but eluded detection.

A variety of thermodynamically competitive packings were in fact observed for the $\mathrm{B} 5 \mathrm{HCl}$ solvates, however, only as disorder components or stacking faults in single crystals, the latter being similar to those seen in aspirin, ${ }^{34 \mathrm{c}}$ promethazine $\mathrm{HCl}^{42}$ and aprepitant. ${ }^{43}$ The combination of intergrown homochiral/ heterochiral stacks (based on $\mathrm{Cl}^{-}$disorder), hydrocarbon layer packings, and alternate solvent orientations frustrated crystal growth of the solvates in some cases to the point where only reflections corresponding to the interlayer $\{100\}$ spacings were observed by flat-plate PXRD (Figure 2a). A crude Bravais-Friedel-Donnay-Harker (BFDH) morphology calculation for S-MeOH and S-nBuOH shows the (100) face to be the morphologically dominant face of the thin blades (Figure 15), a finding consistent with the PXRD data. Not surprisingly, the slowest growing (a) direction of each solvate crystal coincides with the weak hydrocarbon interface layer. Errors in the packing of the hydrocarbon layers along $a$ would give rise to the diffuse scattering and might be observable by SCXRD. It appears, however, that crystal growth, even for the thermodynamically stable methanol solvate, is sufficiently fast that mistakes are also made in the $b$ and $c$ directions, resulting in the intergrowths of homo- and heterochiral $\mathrm{B}^{\circ} \mathrm{H}^{+}$stacks (Figure $7 \mathrm{~b}$, Figure $8 \mathrm{~d}$ ). The problems are far greater for the kinetic solvates, where supersaturation must be consumed very rapidly before nucleation and growth of Form I (or B5) occur. In the end, we identified a relatively narrow range of experimental conditions to selectively crystallize the alcohol solvates without interference from Form I or disproportionation to B5, but in all cases, the single crystals were shown to be defective. Whether structurally pure crystals of the disorder components, i.e., solvate polymorphs, could ever be grown or growth errors are inevitable during crystallization remains to be seen.

With no evidence of other neat forms of $\mathrm{B} 5 \mathrm{HCl}$ having crystallized from solution during the solid form screen, our attention was directed to the alcohol solvates because desolvation has proven to be a productive way to generate novel, solvent-free forms. ${ }^{44-47}$ The crystal energy landscape (Figure 10) appears to suggest that other $\mathrm{B} 5 \mathrm{HCl}$ crystal structures are thermodynamically plausible and some, including ee4553, ee2270, and computational S-MeOH desolvate, ee5411, have cation packing arrangements resembling the solvates (Figure 11). Yet, desolvation of all of the $\mathrm{B} 5 \mathrm{HCl}$ alcohol solvates lead to Form I rather than generating a more closely related polymorph. This raises the question often posed by
CSP studies; why do we not find more polymorphs $?^{48}$ For $\mathrm{B} 5 \mathrm{HCl}$, perhaps Form I is more stable than the packing alternatives at the desolvation temperatures and therefore thermodynamically favored. Alternatively, Form I might be less stable (possibly more stable at the nanoscale ${ }^{49}$ ) and nucleate and grow so much faster than any other packing arrangement that once formed, $\mathrm{B} 5 \mathrm{HCl}$ becomes kinetically trapped in this crystal structure. Clearly, for ultimate control over desolvation pathways and kinetics, more work is needed on systems like $\mathrm{B} 5 \mathrm{HCl}$ to understand the mechanisms underlying phase transformations, crystal nucleation and growth at the molecular level.

4.2. Role of Computational Chemistry for Pharmaceutical Salts. Solid state modeling at the electronic and atomistic level provided vital support for unravelling the complexity of the $\mathrm{B} 5 \mathrm{HCl}$ crystallization behavior and adding confidence to the interpretation of the experimental data. It produced models for the uncharacterized solvates, supported the evidence for disorder, and confirmed that there are a variety of ways that $\mathrm{B} 5 \mathrm{HCl}$ can crystallize that are virtually equivalent in energy within the likely errors. The lattice energy of $\mathrm{B} 5 \mathrm{HCl}$ is a factor of about 3.5 larger than for B5, a similar ratio as found in comparing salts and corresponding cocrystals. ${ }^{50}$ However, in contrast to neutral molecules, hydrates, ${ }^{51}$ or cocrystals, ${ }^{52}$ there has been very little work validating the lattice energy modeling of molecular ionic species, in particular, the balance between the strong electrostatic interactions and polarization of the molecular charge distributions with changes in conformational energy and the weak van der Waals dispersion forces. The calculations of the crystal energy landscape ignore the change in the charge distribution between the gas and crystalline phases, which is very challenging to model for specific crystal structures ${ }^{22,53}$ but leads to considerable reranking of the structures (Figure S10) when the cation conformational energy and charge distribution are modeled within a dielectric constant $\varepsilon=11$ typical for organic salts. ${ }^{25 \mathrm{~b}}$ Periodic electronic structure methods better account for the polarization and molecular flexibility than the model we could use for CSP, but suffer from the increased expense. For example, a single structural optimization (cf. Table S8) takes up to a week on 48 cores of a supercomputing cluster. However, even these calculations, while adequate for confirming crystal structures, ${ }^{54}$ have known deficiencies in calculating energies from the quality of the charge distribution and the uncertainty in the dispersion correction. ${ }^{55}$ Hence the degree of agreement between the two complementary methods is reassuring.

This project was initiated to explore the use of CSP as a complement to the experimental solid form screening of pharmaceutical salts. Although chloride salts are commonly used to deliver basic pharmaceutical molecules ${ }^{56}$ and account for $45 \%$ of the salt structures with pharmaceutically acceptable counterions in the Cambridge Structural Database ${ }^{57}$ and for $42 \%$ of the officinal salts, ${ }^{58}$ the only published CSP studies for chloride salts are pyridinium chloride, ${ }^{59}$ a family of adamantane hydrochlorides, ${ }^{60}$ and thiouronium carboxylic acid monohydrate chloride, the structure of which was correctly predicted by only one method in the sixth blind test of organic crystal structure prediction. ${ }^{61} \mathrm{~B} 5 \mathrm{HCl}$ is obviously more challenging from the size and flexibility of the cation being added to the additional search variables of relative position of the two ions. Nevertheless, our CSP study has shown that if $\mathrm{B} \mathrm{H}^{+}$were only able to adopt the ea conformation, then generating the crystal energy landscape would have been much easier as the $e a$ region 
search converged relatively quickly (Supporting Information, section 3.3, Figure S4), and the energy differences between the fewer unique low energy structures would have been larger, giving a clear prediction of the stable structure (Figure 10 and Figure S8). However, $\mathrm{BSH}^{+}$also adopts the ee conformation, where despite generating 1.5 million structures, Form I was found only once and this search is far from complete ${ }^{62}$ (Supporting Information, section 3.3). This is because the ee conformations give rise to many more layer structures, some of which were apparent in the observed forms and disorder involving homochiral and heterochiral stacks. This observation that some strongly hydrogen-bonded ionic motifs can give rise to a multitude of different three-dimensional packings, whereas others have more specific ways of packing leading to fewer competitive structures, has also been seen in some diastereomeric organic salts. ${ }^{63}$

The more expensive periodic electronic structure calculations, $\mathrm{PBE}-\mathrm{TS} / \mathrm{D} 2$, were effectively used to refine the relative energies of key $\mathrm{B} 5 \mathrm{HCl}$ structures (Table S8), propose the monoalcohol solvate structures (Supporting Information, section 5), and rationalize observed packing disorder of $\mathrm{B} 5 \mathrm{HCl}$ and conformational disorder of the solvent molecules. Even these calculations are not sufficiently accurate to conclude that any polymorphic structure could be more stable than Form I at ambient conditions, nor to eliminate the possibility of further polymorphism of the neat form. Even with accurate free energy calculations, many structures corresponding to different free energy minima are unlikely to remain distinct during the nucleation and growth processes implicated in the transformations of the solvates to Form I. The clear links between the $\mathrm{BSH}^{+}$packings of the solvates and neat form and the extent to which the solvates may be kinetic forms raise the question ${ }^{64}$ whether $\mathrm{B} 5 \mathrm{HCl}$ will adopt the most thermodynamically stable structure.

4.3. Implications for Pharmaceutical Development. Walter McCrone, reflecting on his experiences in producing and characterizing solid forms, famously stated more than 50 years ago, "It is at least this author's opinion that every compound has different polymorphic forms and that, in general, the number of forms known for each compound is proportional to the time and money spent in research on that compound." 65 Today, with ever more powerful experimental tools and increasingly reliable computational methods being applied, oftentimes in tandem, to the solid form screening of small molecule pharmaceuticals, this assertion appears to have stood the test of time. For $\mathrm{B} 5 \mathrm{HCl}$, our pursuit of new polymorphs produced by desolvation identified an impressively large family of alcohol solvates in addition to neat polymorphs and a dihydrate. On a molecular level, the range of solvates we observed is a consequence of the ability of the crystal packing to adapt to progressively larger hydrocarbon tails of the solvent to the point where the hydrocarbon interface becomes too weak.

While we were successful in producing a different nonsolvated polymorph (Form II) by dehydration of $\mathrm{B} 5 \mathrm{HCl}$ dihydrate, none of the alcohol solvates yielded new polymorphs on desolvation. Still, the detailed structural investigation needed to clarify the solvated forms of $\mathrm{B} 5 \mathrm{HCl}$ on the solid form landscape provided valuable lessons. The solid form diversity proved far more complex than initially thought based on cursory PXRD analysis or even as ultimately depicted in the relatively simple interconversion diagram shown in Figure 4. A variety of competitive structures, some merely suggested from the crystal energy landscape of neat $\mathrm{B} 5 \mathrm{HCl}$ and others present in sufficient abundance to be observed as disorder components in single crystals, helped rationalize the problems we encountered in crystal growth, as well as the generally poor diffraction, of the monoalcohol solvates. In fact, there was enough variability in different X-ray crystal structures of S$\mathrm{MeOH}$ and S-iPrOH alone (Table S2) to suggest that no two solvate single crystals are the same. It is clear from the $\mathrm{B} 5 \mathrm{HCl}$ experience that to achieve realistic correlations of structure with pharmaceutical properties, detailed disorder modeling may be required. $^{66}$

Perhaps surprisingly, $\mathrm{B} 5 \mathrm{HCl}$ is by most standards considered to be well-behaved from a drug development perspective. Despite its having polymorphs, a hydrate and solvates, which is not uncommon for molecules that have undergone comprehensive solid form screening, ${ }^{38,58,67}$ this $\mathrm{HCl}$ salt crystallizes with ease in a stable, nonsolvated form (Form I) with excellent solid-state properties. In fact, had salt disproportionation not posed a significant risk to form control in the drug product, the $\mathrm{HCl}$ salt might have been chosen over monomorphic B5 for development. Obviously, until the pharmaceutical relevance of any new phases produced during solid form screening is established, the problems that solid form diversity may present to developing a drug cannot be known. For $\mathrm{B} 5 \mathrm{HCl}$, the solid form landscape ultimately proved to be of little concern, save for salt disproportionation, to developing the 5-HT2a antagonist, yet an enormous effort went into providing such assurance. We are reminded with $\mathrm{B} 5 \mathrm{HCl}$ that there are no standard recipes for effectively carrying out solid form screens; ${ }^{38}$ our success hinged on our ability to adapt the screen to accommodate the physical and chemical properties (solubility, stability) and crystallization behaviors of the $\mathrm{HCl}$ salt. In the end, we chose to incur the added expense of customizing a solid form screen (cf. axitinib ${ }^{68}$ ) to mitigate the risk of having missed an important neat polymorph or hydrate, which could otherwise have appeared later in development, or worse yet, in a marketed product.

\section{CONCLUSIONS}

Industry-standard solid form screening and characterization protocols outright failed to produce a reliable picture of the phase behavior of $\mathrm{B} 5 \mathrm{HCl}$. Only through careful manipulation of experimental conditions to selectively nucleate and grow novel forms of a salt all too willing to crystallize in its most stable anhydrous form and to grow single crystals to sufficient size and quality for detailed X-ray diffraction analysis was the rich solid form landscape of $\mathrm{BSHCl}$ established with the help of computational chemistry. Two neat polymorphs (I and II) were identified, along with a dihydrate, alcohol monosolvates (1:1) from methanol, ethanol, isopropanol, $n$-propanol, $n$ butanol, 2-butanol, $i$-butanol, $n$-pentanol and $n$-octanol, and hemisolvates (2:1) from ethylene and propylene glycol. Classification by hydrogen bonding/ionic coordination gives structures that differ in detail, but there is an overall similarity in the formation of bilayer structures with interdigitating benzisoxazole groups. The calculated crystal energy landscape contains further variations on the ionic layer and hydrophobic packings, showing the potential for the disorder and crystal growth errors, which provided some of the challenges in characterizing the solid forms. The layer structures of the salt account for the range of crystalline forms, their disorder and variability in their highly anisotropic properties. 


\section{ASSOCIATED CONTENT}

\section{S Supporting Information}

The Supporting Information is available free of charge on the ACS Publications website at DOI: 10.1021/acs.cgd.7b00842.

Crystallography (powder, single crystal), crystal structure prediction study details, comparison of the $\mathrm{B} 5 \mathrm{HCl}$ and B5 crystal energy landscapes, computer modeling and structure derivation of $\mathrm{B} 5 \mathrm{HCl}$ solvates, DFT-D chemical shielding calculations, details of the experimental solid form screen, crystallization procedures and solid form characterization (microscopy, thermal analysis, GVS), Form II Rietveld refinement, CSD survey of organic chloride salts (PDF)

\section{Accession Codes}

CCDC 1556378-1556388 and 1565540 contain the supplementary crystallographic data for this paper. These data can be obtained free of charge via www.ccdc.cam.ac.uk/data_request/ cif, or by emailing data_request@ccdc.cam.ac.uk, or by contacting The Cambridge Crystallographic Data Centre, 12 Union Road, Cambridge CB2 1EZ, UK; fax: +44 1223336033.

\section{AUTHOR INFORMATION}

\section{Corresponding Author}

*E-mail: reutzel-edens_susan_m@lilly.com.

\section{ORCID $\odot$}

Doris E. Braun: 0000-0003-0503-4448

Sarah L. Price: 0000-0002-1230-7427

Susan M. Reutzel-Edens: 0000-0003-0806-5565

\section{Notes}

The authors declare no competing financial interest.

\section{ACKNOWLEDGMENTS}

The authors wish to thank Jennifer McMahon, Lori Hilden, David Jackson, Rita Kleemann, Lien Koztecki, David Remick, Aktham Aburub, and Ben Diseroad for supporting the early polymorph screening and characterization work and Stephen Antonysamy for helpful discussions. Profs. C. C. Pantelides and C. S. Adjiman are thanked for the use of CrystalPredictor and CrystalOptimizer codes. The authors' collaboration was funded by Eli Lilly and Company through the Lilly Research Awards Program and the development of the computational infrastructure through the EPSRC EP/K039229/1 and EP/ F03573X/1 and the project benefited from EU COST Action CM1402 "Crystallize". DEB gratefully acknowledges funding by the Elise Richter programme of the Austrian Science Fund (FWF, project V436-N34). DFT-D results presented have been achieved using the HPC infrastructure LEO of the University of Innsbruck.

\section{ABBREVIATIONS}

2-BuOH, 2-butanol; CP, cross-polarization; CSP, crystal structure prediction; DFT-D, dispersion-corrected density functional theory; DSC, differential scanning calorimetry; $\mathrm{EtOH}$, ethanol; EtGly, ethylene glycol; FTIR, Fourier transform infrared; GVS, gravimetric vapor sorption; i-BuOH, isobutanol; i-PrOH, isopropanol; MAS, magic angle spinning; $\mathrm{MeOH}$, methanol; $n$-BuOH, $n$-butanol; NMR, nuclear magnetic resonance; $n$-OcOH, $n$-octanol; $n$-PeOH, $n$-pentanol; n-PrOH, n-propanol; PrGly, propylene glycol; PXRD, powder $\mathrm{X}$-ray diffraction; $\mathrm{RH}$, relative humidity; $\mathrm{RT}$, room temperature; SCXRD, single crystal X-ray diffraction; SEM, scanning electron microscopy; ssNMR, solid-state nuclear magnetic resonance; TGA, thermogravimetric analysis

\section{REFERENCES}

(1) ANDAs: Pharmaceutical Solid Polymorphism: Chemistry, Manufacturing, and Controls Information. (CDER) U.S. Department of Health and Human Services, Food and Drug Administration, 2007.

(2) Bond, A. D.; Solanko, K. A.; Parsons, S.; Redder, S.; Boese, R. CrystEngComm 2011, 13 (2), 399-401.

(3) Braun, D. E.; Oberacher, H.; Arnhard, K.; Orlova, M.; Griesser, U. J. CrystEngComm 2016, 18 (22), 4053-4067.

(4) Bucar, D. K.; Lancaster, R. W.; Bernstein, J. Angew. Chem., Int. Ed. 2015, 54 (24), 6972-6993.

(5) Braun, D. E.; McMahon, J. A.; Koztecki, L. H.; Price, S. L.; Reutzel-Edens, S. M. Cryst. Growth Des. 2014, 14 (4), 2056-2072.

(6) (a) Price, S. L.; Braun, D. E.; Reutzel-Edens, S. M. Chem. Commun. 2016, 52, 7065-7077. (b) Price, S. L.; Reutzel-Edens, S. M. Drug Discovery Today 2016, 21 (6), 912-923.

(7) (a) Cruz-Cabeza, A. J.; Day, G. M.; Jones, W. Chem. - Eur. J. 2009, 15 (47), 13033-13040. (b) Hasell, T.; Culshaw, J. L.; Chong, S. Y.; Schmidtmann, M.; Little, M. A.; Jelfs, K. E.; Pyzer-Knapp, E. O.; Shepherd, H.; Adams, D. J.; Day, G. M.; Cooper, A. I. J. Am. Chem. Soc. 2014, 136 (4), 1438-1448. (c) Braun, D.; Griesser, U. Cryst. Growth Des. 2016, 16 (10), 6111-6121.

(8) Coelho, A. A. J. Appl. Crystallogr. 2003, 36, 86-95.

(9) Markvardsen, A. J.; David, W. I. F.; Johnson, J. C.; Shankland, K. Acta Crystallogr., Sect. A: Found. Crystallogr. 2001, 57, 47-54.

(10) David, W. I. F.; Shankland, K.; van de Streek, J.; Pidcock, E.; Motherwell, W. D. S.; Cole, J. C. J. Appl. Crystallogr. 2006, 39, 910915.

(11) Pawley, G. S. J. Appl. Crystallogr. 1981, 14, 357-361.

(12) Rietveld, H. M. J. Appl. Crystallogr. 1969, 2, 65-71.

(13) Coelho, A. A. Topas Academic, V5; Coelho Software: Brisbane, 2012.

(14) Metz, G.; Wu, X. L.; Smith, S. O. J. Magn. Reson., Ser. A 1994, 110 (2), 219-227.

(15) Fung, B. M.; Khitrin, A. K.; Ermolaev, K. J. Magn. Reson. 2000, 142 (1), 97-101.

(16) Antzutkin, O. N. Prog. Nucl. Magn. Reson. Spectrosc. 1999, 35 (3), 203-266.

(17) Cruz-Cabeza, A. J.; Bernstein, J. Chem. Rev. 2014, 114 (4), 2170-2191.

(18) Thompson, H.; Day, G. Chem. Sci. 2014, 5 (8), 3173-3182.

(19) (a) Pantelides, C.; Adjiman, C.; Kazantsev, A. Prediction and Calculation of Crystal Structures: Methods and Applications. Topics in Current Chemistry; Springer, 2014; Vol. 345, pp 25-58 (b) Karamertzanis, P. G.; Pantelides, C. C. Mol. Phys. 2007, 105 (2-3), 273291.

(20) Kazantsev, A. V.; Karamertzanis, P. G.; Adjiman, C. S.; Pantelides, C. C. J. Chem. Theory Comput. 2011, 7 (6), 1998-2016.

(21) Stone, A. J. J. Chem. Theory Comput. 2005, 1 (6), 1128-1132.

(22) Price, S. L.; Leslie, M.; Welch, G. W. A.; Habgood, M.; Price, L. S.; Karamertzanis, P. G.; Day, G. M. Phys. Chem. Chem. Phys. 2010, 12 (30), 8478-8490.

(23) Williams, D. E. J. Comput. Chem. 2001, 22 (11), 1154-1166.

(24) Day, G. M. $\mathrm{Cl}^{-}$potentials, personal communication, 2013.

(25) (a) Cossi, M.; Scalmani, G.; Rega, N.; Barone, V. J. Chem. Phys. 2002, 117 (1), 43-45. (b) Cooper, T. G.; Hejczyk, K. E.; Jones, W.; Day, G. M. J. Chem. Theory Comput. 2008, 4 (10), 1795-1805.

(26) Clark, S. J.; Segall, M. D.; Pickard, C. J.; Hasnip, P. J.; Probert, M. J.; Refson, K.; Payne, M. C. Z. Kristallogr. - Cryst. Mater. 2005, 220 (5-6), 567-570.

(27) Perdew, J. P.; Burke, K.; Ernzerhof, M. Phys. Rev. Lett. 1996, 77 (18), 3865-3868.

(28) Vanderbilt, D. Phys. Rev. B: Condens. Matter Mater. Phys. 1990, 41 (11), 7892-7895.

(29) Tkatchenko, A.; Scheffler, M. Phys. Rev. Lett. 2009, 102 (7), 073005 .

(30) Grimme, S. J. Comput. Chem. 2006, 27 (15), 1787-1799. 
(31) Pickard, C.; Mauri, F. Phys. Rev. B: Condens. Matter Mater. Phys. 2001, 63 (24), 245101.

(32) Macrae, C. F.; Edgington, P. R.; McCabe, P.; Pidcock, E.; Shields, G. P.; Taylor, R.; Towler, M.; van de Streek, J. J. Appl. Crystallogr. 2006, 39, 453-457.

(33) (a) Gelbrich, T.; Hursthouse, M. B. CrystEngComm 2005, 7, 324-336. (b) Gelbrich, T.; Threlfall, T. L.; Hursthouse, M. B. CrystEngComm 2012, 14 (17), 5454-5464.

(34) (a) Hoser, A. A.; Sovago, I.; Lanza, A.; Madsen, A. O. Chem. Commun. 2017, 53 (5), 925-928. (b) Thomas, L. H.; Craig, G. A.; Morrison, C. A.; Reilly, A. M.; Wilson, C. C. Cryst. Growth Des. 2011, 11 (6), 2045-2049. (c) Bond, A. D.; Boese, R.; Desiraju, G. R. Angew. Chem., Int. Ed. 2007, 46 (4), 618-622.

(35) Newman, A. Org. Process Res. Dev. 2013, 17 (3), 457-471.

(36) Morrison, H.; Quan, B.; Walker, S.; Hansen, K.; Nagapudi, K.; Cui, S. Org. Process Res. Dev. 2015, 19 (12), 1842-1848.

(37) Muller, P. Crystallogr. Rev. 2009, 15 (1), 57-83.

(38) Cruz-Cabeza, A. J.; Reutzel-Edens, S. M.; Bernstein, J. Chem. Soc. Rev. 2015, 44, 8619-8635.

(39) Neumann, M. A.; van de Streek, J.; Fabbiani, F. P. A.; Hidber, P.; Grassmann, O. Nat. Commun. 2015, 6, 7793.

(40) Srirambhatla, V. K.; Guo, R; Price, S. L.; Florence, A. J. Chem. Commun. 2016, 52, 7384-7386.

(41) Price, L. S.; McMahon, J. A.; Lingireddy, S. R.; Lau, S. F.; Diseroad, B. A.; Price, S. L.; Reutzel-Edens, S. M. J. Mol. Struct. 2014, 1078, 26-42.

(42) Borodi, G.; Pop, M. M.; Onija, O.; Filip, X. Cryst. Growth Des. 2012, 12 (12), 5846-5851.

(43) Braun, D. E.; Gelbrich, T.; Kahlenberg, V.; Laus, G.; Wieser, J.; Griesser, U. J. New J. Chem. 2008, 32 (10), 1677-1685.

(44) (a) Fours, B.; Cartigny, Y.; Petit, S.; Coquerel, G. Faraday Discuss. 2015, 179, 475-488. (b) Minkov, V.; Beloborodova, A.; Drebushchak, V.; Boldyreva, E. Cryst. Growth Des. 2014, 14 (2), 513522.

(45) Braun, D. E.; Koztecki, L. H.; McMahon, J. A.; Price, S. L.; Reutzel-Edens, S. M. Mol. Pharmaceutics 2015, 12 (8), 3069-3088.

(46) Braun, D. E.; Gelbrich, T.; Wurst, K.; Griesser, U. J. Cryst. Growth Des. 2016, 16 (6), 3480-3496.

(47) Braun, D. E.; Kahlenberg, V.; Gelbrich, T.; Ludescher, J.; Griesser, U. J. CrystEngComm 2008, 10 (11), 1617-1625.

(48) Price, S. L. Acta Crystallogr., Sect. B: Struct. Sci., Cryst. Eng. Mater. 2013, 69, 313-328.

(49) Belenguer, A.; Lampronti, G.; Cruz-Cabeza, A.; Hunter, C.; Sanders, J. Chem. Sci. 2016, 7 (11), 6617-6627.

(50) Mohamed, S.; Tocher, D. A.; Price, S. L. Int. J. Pharm. 2011, 418 (2), 187-198.

(51) Braun, D. E.; Karamertzanis, P. G.; Price, S. L. Chem. Commun. 2011, 47 (19), 5443-5445.

(52) Karamertzanis, P. G.; Kazantsev, A. V.; Issa, N.; Welch, G. W. A.; Adjiman, C. S.; Pantelides, C. C.; Price, S. L. J. Chem. Theory Comput. 2009, 5 (5), 1432-1448.

(53) Welch, G. W. A.; Karamertzanis, P. G.; Misquitta, A. J.; Stone, A. J.; Price, S. L. J. Chem. Theory Comput. 2008, 4 (3), 522-532.

(54) (a) van de Streek, J.; Neumann, M. A. Acta Crystallogr., Sect. B: Struct. Sci. 2010, 66, 544-558. (b) Binns, J.; Healy, M. R.; Parsons, S.; Morrison, C. A. Acta Crystallogr., Sect. B: Struct. Sci., Cryst. Eng. Mater. 2014, 70, 259-267. (c) Florence, A. J.; Bardin, J.; Johnston, B.; Shankland, N.; Griffin, T. A. N.; Shankland, K. Zeitschrift fur Kristallographie 2009, 2009, 215-220.

(55) Nyman, J.; Pundyke, O. S.; Day, G. M. Phys. Chem. Chem. Phys. 2016, 18 (23), 15828-15837.

(56) Paulekuhn, G. S.; Dressman, J. B.; Saal, C. J. Med. Chem. 2007, 50 (26), 6665-6672.

(57) Haynes, D. A.; Jones, W.; Motherwell, W. D. S. J. Pharm. Sci. 2005, 94 (10), 2111-2120.

(58) Braun, D. E. Ph.D. thesis, University of Innsbruck, 2008.

(59) van de Streek, J.; Neumann, M.; Perrin, M. CrystEngComm 2010, 12 (11), 3827-3833.
(60) (a) Mohamed, S. Acta Crystallogr. E 2016, 72, 1348-1352. (b) Mohamed, S.; Karothu, D. P.; Naumov, P. Acta Crystallogr., Sect. B: Struct. Sci., Cryst. Eng. Mater. 2016, 72, 551-561.

(61) Reilly, A. M.; Cooper, R. I.; Adjiman, C. S.; Bhattacharya, S.; Boese, A. D.; Brandenburg, J. G.; Bygrave, P. J.; Bylsma, R.; Campbell, J. E.; Car, R.; Case, D. H.; Chadha, R.; Cole, J. C.; Cosburn, K.; Cuppen, H. M.; Curtis, F.; Day, G. M.; DiStasio, R. A., Jr; Dzyabchenko, A.; van Eijck, B. P.; Elking, D. M.; van den Ende, J. A.; Facelli, J. C.; Ferraro, M. B.; Fusti-Molnar, L.; Gatsiou, C.-A.; Gee, T. S.; de Gelder, R.; Ghiringhelli, L. M.; Goto, H.; Grimme, S.; Guo, R.; Hofmann, D. W. M.; Hoja, J.; Hylton, R. K.; Iuzzolino, L.; Jankiewicz, W.; de Jong, D. T.; Kendrick, J.; de Klerk, N. J. J.; Ko, H.Y.; Kuleshova, L. N.; Li, X.; Lohani, S.; Leusen, F. J. J.; Lund, A. M.; Lv, J.; Ma, Y.; Marom, N.; Masunov, A. E.; McCabe, P.; McMahon, D. P.; Meekes, H.; Metz, M. P.; Misquitta, A. J.; Mohamed, S.; Monserrat, B.; Needs, R. J.; Neumann, M. A.; Nyman, J.; Obata, S.; Oberhofer, H.; Oganov, A. R.; Orendt, A. M.; Pagola, G. I.; Pantelides, C. C.; Pickard, C. J.; Podeszwa, R.; Price, L. S.; Price, S. L.; Pulido, A.; Read, M. G.; Reuter, K.; Schneider, E.; Schober, C.; Shields, G. P.; Singh, P.; Sugden, I. J.; Szalewicz, K.; Taylor, C. R.; Tkatchenko, A.; Tuckerman, M. E.; Vacarro, F.; Vasileiadis, M.; Vazquez-Mayagoitia, A.; Vogt, L.; Wang, Y.; Watson, R. E.; de Wijs, G. A.; Yang, J. Z.; Zhu, Q.; Groom, C. R. Acta Crystallogr., Sect. B: Struct. Sci., Cryst. Eng. Mater. 2016, 72, 439-459.

(62) Case, D. H.; Campbell, J. E.; Bygrave, P. J.; Day, G. M. J. Chem. Theory Comput. 2016, 12 (2), 910-924.

(63) (a) Karamertzanis, P. G.; Anandamanoharan, P. R.; Fernandes, P.; Cains, P. W.; Vickers, M.; Tocher, D. A.; Florence, A. J.; Price, S. L. J. Phys. Chem. B 2007, 111 (19), 5326-5336. (b) Wu, H.; Habgood, M.; Parker, J. E.; Reeves-McLaren, N.; Cockcroft, J. K.; Vickers, M.; West, A. R.; Jones, A. G. CrystEngComm 2013, 15 (10), 1853-1859.

(64) Hylton, R.; Tizzard, G.; Threlfall, T.; Ellis, A.; Coles, S.; Seaton, C.; Schulze, E.; Lorenz, H.; Seidel-Morgenstern, A.; Stein, M.; Price, S. L. J. Am. Chem. Soc. 2015, 137 (34), 11095-11104. Antoniadis, C. D.; D'Oria, E.; Karamertzanis, P. G.; Tocher, D. A.; Florence, A. J.; Price, S. L.; Jones, A. G. Chirality 2010, 22 (4), 447-455.

(65) McCrone, W. C., Polymorphism. In Physics and Chemistry of the Organic Solid State, Fox, D.; Labes, M. M.; Weissberger, A., Eds. Wiley Interscience: New York, 1965; Vol. II, pp 725-767.

(66) Bond, A. D. CrystEngComm 2012, 14 (7), 2363-2366.

(67) Stahly, G. P. Cryst. Growth Des. 2007, 7 (6), 1007-1026.

(68) (a) Campeta, A. M.; Chekal, B. P.; Abramov, Y. A.; Meenan, P. A.; Henson, M. J.; Shi, B.; Singer, R. A.; Horspool, K. R. J. Pharm. Sci. 2010, 99 (9), 3874-3886. (b) Chekal, B.; Campeta, A.; Abramov, Y.; Feeder, N.; Glynn, P.; McLaughlin, R; Meenan, P.; Singer, R. Org. Process Res. Dev. 2009, 13 (6), 1327-1337. 